\title{
Set-Based Concurrent Engineering Innovation Roadmap (SBCE IR): a case on Adiabatic Humidification System
}

\author{
Endris Kerga $^{\mathrm{a}, \mathrm{b} *}$, Marco Taisch ${ }^{\mathrm{a}, 1}$, Sergio Terzi ${ }^{\mathrm{c}, 2}$, Walter Bessega ${ }^{\mathrm{b}, 3}$ and Alberto Rosso ${ }^{\mathrm{b}, 4}$ \\ ${ }^{a}$ Politecnico di Milano, Piazza Leonardo da Vinci 32, 20133 Milan, Italy; ${ }^{b}$ Carel Industries, Via \\ della Industria 11, 35020 Brugine, Italy; ${ }^{c}$ Dipartimento di Ingegneria, Università Degli Studi di \\ Bergamo, Marconi 5, 24044 Dalmine (BG), Italy
}

(Received 2 May 2013; accepted 25 February 2014)

\begin{abstract}
Set-Based Concurrent Engineering (SBCE) is an element of lean practice in product development (PD), and it is composed of principles to apply it at early phase of a design process. However, executing the principles demands extensive efforts in practice. Thus, a systematic methodology is required to identify and prioritize potential areas (area in this paper is a generic term used to refer to subsystems, components or design factors or parameters a designer is applying SBCE process to explore, communicate and evaluate sets of solutions to satisfy a customer requirement or to solve a particular problem) where SBCE brings its utmost benefits. This paper proposes such a methodology called SBCE Innovation Roadmap (SBCE IR) that is used as a guideline by product designers to begin SBCE processes. A case study on Adiabatic Humidification System (AHS) is discussed to elaborate the application of the methodology in a real product system. Furthermore, by using the roadmap, a rack subsystem is selected to show how to use SBCE IR as an input for SBCE process, and further explore and evaluate innovative design concepts. Finally, an open questionnaire is prepared and interviews are made with experts to assess the advantages, applicability, and limitations of the methodology.
\end{abstract}

Keywords: Set-Based Concurrent Engineering; Quality Function Deployment; Theory of Inventive Problem Solving; contradictions; Adiabatic Humidification System

\section{Introduction}

In early stage of a design process, Set Based Concurrent Engineering (SBCE) is a popular element of lean practice in product development (PD) (Al-Ashaab et al., 2010; Morgan \& Liker, 2006; Oosterwal, 2010; Sobek, Ward, \& Liker, 1999; Ward, Liker, Cristiano, \& Sobek, 1995; Ward, Shook, \& Sobek, 2007). It is defined as when designers "reason, develop and communicate about sets of solutions in parallel and relatively independent" (Sobek, 1997). It involves three basic principles (Sobek et al., 1999): (1) "Map the design space" or principle of exploration, which aims to achieve a thorough understanding of sets of design possibilities for subsystems, or what design theorists called exploring the "design space" (Maher \& Poon, 1996; Smithers, 1989; Zeng \& Cheng, 1991). (2) "Integrate by intersection" or principle of set-based communication, which ensures that subsystem solutions are defined that are workable/compatible to all functional groups

*Corresponding author. Email: endris.kerga @mail.polimi.it; endris.kerga@ carel.com 
involved. (3) "Establish feasibility before commitment" or principle of convergence that prescribes an aggressive elimination of inferior design sets.

Researches argued that SBCE has several advantages (Kennedy \& Harmon, 2008; Khan et al., 2011; Raudberget, 2010; Sobek et al., 1999; Ward et al., 1995). These are: (1) reduction of product and process costs, by searching cheaper alternatives, adding the right features, and reducing late/costly reworks; (2) reduction of development time, by reusing previous knowledge and/or avoiding delays caused by late changes; (3) improve innovation potential, by exploring alternative solutions and making ideas successful the first time; (4) better communication, by effectively using data and proven knowledge among design teams (e.g., trade-off and limit curves); (5) avoid design risks, by increasing the probability of success due to the consideration of larger sets; and (6) facilitate learning.

Although the principles of SBCE are sound and the claimed benefits are promising, there are fundamental impediments for its practical success. Among which, this paper tries to provide an answer for an important question that is lacking from the existing literature, i.e., how designers can identify and prioritize areas in a product system (at subsystem and component levels) where SBCE should be applied?

In the reminder of this paper, in Section 2, the limitations of SBCE, review of related works, contributions, originality, and objectives of this paper are discussed. In Section 3, the proposed SBCE Innovation Roadmap (SBCE IR) methodology is presented and the associated steps are detailed. The case study conducted on Adiabatic Humidification System (AHS) to apply the methodology is described in Section 4. In Section 5, the SBCE process conducted in the selected subsystem (rack subsystem) is discussed along with the benefits obtained. In Section 6, the validation of the SBCE IR methodology and the discussion of its effectiveness are presented. Finally, in Section 7, conclusions and future researches to improve the SBCE IR methodology are explained.

\section{State of the art, research contributions, and objectives}

\subsection{SBCE and its limitations}

As many researches argue, the principles of SBCE are sensible during early phases of a design process and some evidences are reported on the benefits for industries. Nonetheless, SBCE is not yet widely accepted as an industrial practice. The practical challenges and research gaps addressed in this paper are summarized as follows:

1. SBCE is an extensive process: To conduct an SBCE process, designers should go through extensive phases such as exploring, communicating, testing, and evaluating multiple sets in parallel. Doing all these require considerable time, investment, and capabilities (Rossi, Kerga, Taisch, \& Terzi, 2012). Terwiesch, Loch, and De Meyer (2002) and Bogus, Molenaar, and Diekmann (2005) underscored the extensive nature of SBCE strategy, and asserted that it should be used when the cost of pursuing it is cheaper than the value it can create. Ford and Sobek (2005) also proposed a real option model to find the optimal number of sets to consider, limiting the efforts needed to conduct SBCE. Thus, adoption of SBCE should not be based on a random choice, and there is not a guarantee that any such initiative will be a success (Raudberget, 2010). Therefore, there is a need for a systematic methodology to identify and prioritize areas where SBCE should be applied to maximize its benefits.

2. SBCE and its limits for innovation: In the extant literature, SBCE has strictly been related to the use of trade-offs (Sobek et al., 1999). The uses of trade-offs are crucial in SBCE to make decision based on visible data and knowledge (Ward et al., 2007). 
However, established theories of innovation argue that using and accepting tradeoffs restrict the level of innovation (Altshuller, 1984; Hua, Yang, Coulibaly, \& Zhang, 2006; Sheng \& Kok-Soo, 2010). Altshuller, in his prominent Theory of Inventive Problem Solving (TRIZ), underscores the limitation of accepting tradeoffs in design (Altshuller, 1984, 1994, 1999; Hua et al., 2006). In TRIZ, trade-offs or compromises are not accepted, rather they are eliminated if innovative design solutions are sought to be discovered. Lean movement has been associated with increasing efficiency by eliminating non-value adding activities (Womack \& Jones, 2005). However, this argument is predominately related to lean application in manufacturing, where the value of a product is already defined. In PD, the principles of lean are not only related to increasing efficiency but also enhancing innovation or creating more value to customers through exploring unexpected or unique concepts that can push existing technology performances (Oppenheim, 2004). The influence of SBCE in innovation is connected to its first principle "mapping the design space or exploration" (Khan et al., 2011; Sobek et al., 1999). Paradoxically however, if solutions are explored and evaluated based on performance trade-offs, the intent of offering innovative solutions will be limited.

3. Psychological inertia (PI) or Mental inertia: This is a phenomenon explained in TRIZ where designers often tend to explore solutions within known design spaces (Kowalick, 1998). PI is another practical and expected challenge to do the first principle of SBCE "mapping design space or principle of exploration." In particular, considering that $80 \%$ of new design projects are based on minor or small improvements from existing technologies, it often becomes unlikely for designers to observe "out of the box" or innovative solutions (Altshuller 1984, 1994; Kowalick, 1998). If SBCE implementation is subjected to trade-off and PI, one expects that the innovation potential of SBCE is less significant. Therefore, SBCE has to be integrated along with established theories of innovation to enhance creativity while its implementation.

\subsection{Review of related works}

Although SBCE appears in the literature in the 1990s based on studies of Toyota's PD (Sobek et al., 1999; Ward et al., 1995), previous researches have been concerned to improve the effectiveness and efficiency of early phases of design. Moreover, the gaps identified in Section 2.1 have partially been addressed in past researchers. The main previous works are discussed in the following subsections.

\subsubsection{Classical TRIZ}

As a theory for idea creation in the conceptual design processes of products, Altshuller proposed a method of solving invention-specific problems (TRIZ; a Russian acronym for Theory of Inventive Problem Solving) (Altshuller, 1984, 1994, 1999). This method solves technical problems and offers innovative product structures by using a knowledge base built from the analyses of approximately 2.5 million patents, primarily on mechanical design. TRIZ argues that most genuine innovations are the results of resolving contradictions between system requirements. TRIZ effectively models and resolves contradictions between customer requirements using its formulated tools such as the "40 inventive principles," the "principles of separation," and the "substance-field model" (Savransky, 2000). In this way, TRIZ shows its potential for supporting the exploration of 
innovative concepts. However, in a product system, there could be several contradictions to overcome. Classical TRIZ does not provide a method to systematically prioritize contradictions. Therefore, although it can support to identify potential areas for applying SBCE while generating conceptual solutions, it gives little guidance for prioritizing or ranking the most appropriate contradictions to work on.

\subsubsection{OTSM}

OTSM is the Russian acronym for General Theory of Powerful Thinking; it is an evolution of classical TRIZ that provides a hierarchical structure in order to identify the most critical problem (Khomenko, De Guio, Lelait, \& Kaikov, 2007). Cavallucci and Khomenko claim that one of the key issues for OTSM is to reduce the amount of problems to be solved in order to solve a complex network of problems (Cavallucci \& Khomenko, 2007). According to this purpose, several instruments and models have been proposed to address this issue under the names of Networks of Problems (NoP) and Problem Flow Network (PFN) approaches (Khomenko et al., 2007). The Network of Contradiction (NoC) is a subsequent interpretation of the NoP/PFN and integrates information about the contradictory requirements in the form of cause and effect relationships (Khomenko et al., 2007). OTSM is very useful to represent and model real/complex problems and enable to identify the root contradiction to overcome. However, OTSM has two important limitations. First, it does not provide a systematic means to choose the most appropriate contradiction to work on and is biased on the subjective decision of problem solvers (Baldussu, Becattini, \& Cascini, 2011). Second, OTSM is a problem-solving method rather than a planning method; it starts with a particular problem and expands to subproblems to map NoP and NoC. In a product system however, there can be contradictions which are unrelated to each other. OTSM lacks to provide a system view of the whole contradictions. Thus, to provide a robust methodology that answers "where to apply SBCE based on contradictions?" OTSM cannot fulfill the required guideline.

\subsubsection{Integrated models of QFD and TRIZ}

As a procedure to incorporate customer needs into product concepts in product planning, Quality Function Deployment (QFD) has been widely used (Akao \& Mazur, 2003). QFD is an effective tool for product concept determination in product planning processes. Although QFD has been considered an effective planning tool, there is a shortcoming. It cannot clearly indicate that part of a product to which technological innovation should be applied. In order to overcome the shortcoming of QFD, several researchers focus on integrating QFD and TRIZ (Hua et al., 2006; Shi \& She, 2008).

To make the integrated models of QFD and TRIZ work, the target quality set by QFD must be translated into technical contradictions. However, to rank and prioritize contradictions, previous researches still largely focus on subjective judgments of human designers. As a result of this shortcoming, simply combining QFD and TRIZ runs the risk of falling into a random luck (Kline \& Rosenberg, 1986). Related to this issue, other researchers developed systematic approaches for bridging the gap between QFD and TRIZ to rank contradictions (Wang, Chen, Lin, \& Wang, 2005; Yamashina, Ito, \& Kawada, 2002). These advanced works, however, have another limitation. They only capture some resultant contradictions appeared on the House of Quality (HOQ), for example, as tradeoff relationships (contradictions) among customer requirements. In practice, it is often the case that a contradiction relationship may be caused by not just one but several different 
technical contradictions located in various parts of a base product, and contradictions are themselves interrelated. In such circumstances, it seems that the conventional approaches cannot always identify the root cause of the problems and may result in a tedious iteration process that reveals and resolves those problems one by one (Mizuyama \& Ishida, 2007).

\subsection{Previous works and SBCE}

Apart from the above discussions on the contributions of previous works and their limitations, it is important to observe the previous works from SBCE perspective to completely understand the contributions of this paper.

For instance, integrating QFD into TRIZ helps to plan improvement areas based on contradictions and future support to explore innovative design concepts. In real design practice, however, design of a product is distributed to subsystem teams, and if each subsystem team explores its own alternative concepts, teams have to communicate and converge into workable optimal final system solution. Classical TRIZ, OTSM, and integrated models of QFD and TRIZ do not provide how communication and convergence should be executed. On other hand, SBCE provides effective communication and convergence principles and associated tools.

Regarding the current state of SBCE's literature, the missing aspects can be seen from two sides. First, SBCE lacks to provide designers on how to identify, prioritize, and plan improvement areas in a product system where it brings the most benefit. Second, SBCE is not a paradigm to foster innovation during exploration phase - it requires structured integration with already established theory of innovation such as TRIZ.

Table 1 summarizes the pros and cons of the previous works and existing literature of SBCE. Four aspects can be considered: (1) identification of areas to apply SBCE, where it shows whether previous works and SBCE are effective in helping designers to focus where SBCE should be applied; (2) prioritization and ranking scheme/s to apply $S B C E$, where it shows whether previous works and SBCE are effective in helping designers to rank areas for SBCE implementation; (3) exploration of innovative concepts, where it shows whether previous works and SBCE are effective in helping designers to explore innovative ideas during SBCE implementation; (4) communication and convergence, where it shows whether previous works and SBCE are effective in helping design teams to communicate about sets and facilitate convergence.

\subsection{Contributions/originality and research objectives}

There are two methodological contributions in this paper. First, previous works have focused on contradictions to identify improvement areas to create innovation. Nevertheless, there are still gaps that are not addressed in identification and prioritization aspects (see Table 1). In this regard, this paper advances from existing literature by filling these gaps. In particular, the proposed systematic methodology (SBCE IR) enables to identify both related and unrelated contradictions in a product system, and provides analytical prioritization scheme of contradictions for further SBCE implementation.

Second, this paper has a contribution and originality regarding the utilization of the synergies that exists between TRIZ, QFD, and SBCE. QFD supports SBCE to integrate and structure customer requirements into technical quality characteristics. TRIZ helps SBCE to focus on contradictions and proposes guidelines to formalize the search efforts for innovative solutions. In particular, TRIZ contributes to the first principle of SBCE to explore innovative concepts. On the other hand, SBCE's principles and its enabling tools 


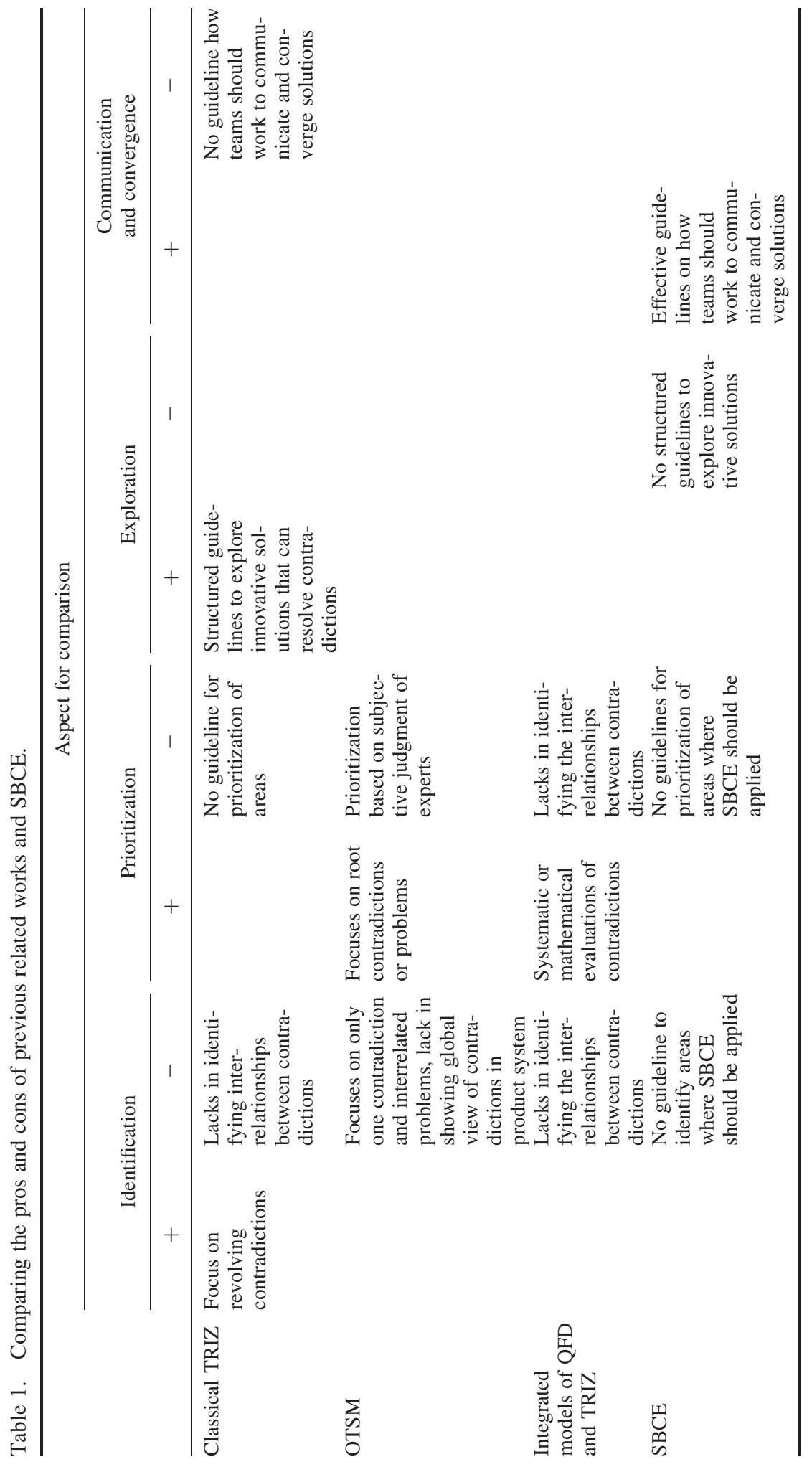


(trade-off curve, checklists, and limit curves) help design teams to communicate and make effective decision to eliminate incompatible, infeasible, and inferior solutions (i.e., convergence). As a result, there are value-adding synergies between QFD, TRIZ, and SBCE. These important synergies have not been sufficiently addressed in previous works (Bhushan, 2007). This paper advances the current state of the art by utilizing the synergies and proposes a methodological contribution to make the implementation of SBCE more structured, practical, and value adding.

\section{SBCE Innovation Roadmap}

The methodology proposed in this paper is called SBCE IR. The terms "Innovation" and

"Roadmap" are used purposefully to reflect the intended purposes of the methodology.

"Innovation" at early stage of design is well understood as series of cycles through which teams explore solutions and iteratively arrive at a final result (Hey, Joyce, \& Beckman, 2007). Novelty (i.e., how unusual the solutions generated are) and variety (i.e., distinctiveness of the solutions generated) are measures of exploration effectiveness (Shah, Vargas-Hernandez, \& Smith, 2002). However, in the current SBCE literature, as explained in Section 2.1, there is no discussion on how it supports designers to improve these measures. If SBCE implementation integrates with principles of TRIZ, the effectiveness measures can presumably be improved. The term "Innovation," therefore, is used to underline the role of TRIZ in SBCE IR.

"Roadmap" could be described as a planning process that guides decision-makers in identifying and evaluating strategic investment alternatives (Garcia \& Bray, 1997). Roadmaps provide the "know-what" (to plan what improvements to do), the "knowwhy" (to rationalize why certain improvements have to be done), and the "know-how" (to guide on how to achieve the planned improvements) (Phaal, Farrukh, \& Probert, 2010). SBCE IR is a methodology to plan SBCE, answering the "what," the "why," and the "how." The focus on contradictions answers what problems designers have to focus on. Predefined criteria are used in SBCE IR to rank contradictions (see Section 3.1) to answer why certain contradictions need priority than others. SBCE IR also provides answer for how solutions are explored and converged. In particular, the use of TRIZ principles and tools allow designers to explore ideas. The principles and tools of SBCE can be used to facilitate the elimination of incompatible and infeasible solutions, and make true convergence. The term "Roadmap" is used to imply the above planning role of SBCE IR.

\subsection{Assumptions and criteria}

Before going in detail on the SBCE IR steps, the criteria and assumptions taken for its construction are discussed as follows:

- Identification of system contradictions leads to improvement areas. The SBCE IR bases on identifying system contradictions for a product. Identifying system contradictions will instigate potential areas where SBCE can be executed. The exploration of possible solutions can be supported by the principles and tools of TRIZ to overcome contradictions (Altshuller, 1984). Then, the remaining SBCE processes (i.e., communication, testing, and convergence) will follow to arrive at a final solution.

- Improvement areas should be prioritized based on customer-value information. It is not uncommon that designers spent considerable amount of their time developing 
features that the customers are not interested in (McManus (2005) and Rossi, Kerga, Taisch, and Terzi (2011). Thus, information on customer value is paramount to be integrated before starting on a particular SBCE process. Once contradictory requirements are identified, customers' judgment on importance can be used as one criterion to prioritize contradictions (i.e., how significant will solving a contradiction be for customers?).

- Improvement areas should be prioritized based on competitive advantages. Often, new requirements, ideas, and innovation potentials arise from competitors, technology trends, and internal brainstorming. So, while building the SBCE IR, competitor analysis is used as an additional criterion to prioritize contradictions (i.e., how important will solving a contradiction be for competitiveness?). Note that, the criteria based on customer value and competitive advantages might be in conflict. A contradiction may be important for customer value but less important for competition, and vice versa. In order to avoid this conflict, in SBCE IR, the aggregated values of both are taken to prioritize contradictions.

\subsection{Steps to build SBCE IR for a product}

Six steps are needed to build SBCE IR for a product as shown in Figure 1. The steps are facilitated by prevalent logics, methods, and tools. QFD is used to have a panoramic view of the steps and simplify the execution of the steps. Figure 2 shows an example of the HOQ excerpted from the case product to facilitate the after-mentioned discussions on the steps of SBCE IR.

\section{Step 1: Identify customer requirements and assign importance}

The first step is to capture customer value in terms of requirements. Then, evaluating and assigning importance or weight to each identified requirement. The requirements are classified into two levels: macro-requirements and micro-requirements (see Figure 2). Macro-requirements $\left(r_{i}\right.$, where $\left.i=1,2,3, \ldots, n\right)$ are general characteristics of a product that should be fulfilled to satisfy the users. For each macro-requirement, detail

characteristics are defined as micro-requirements $\left(r_{j}\right.$, where $\left.j=1,2,3, \ldots, n\right)$. To determine weights $W\left(r_{i}\right)$ and $W\left(r_{j}\right)$, the prevalent method of analytical hierarchical

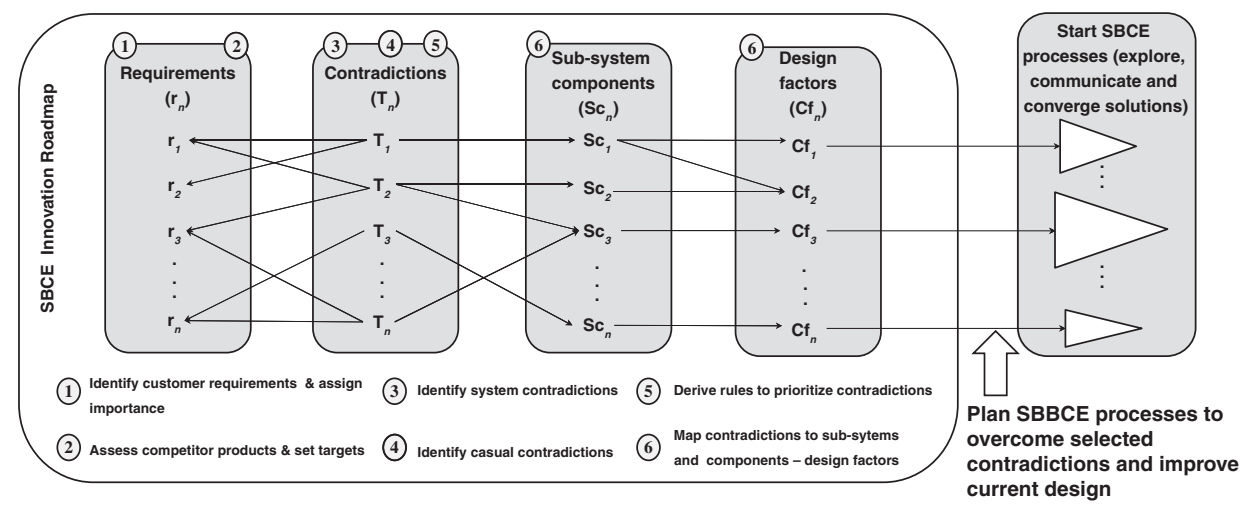

Figure 1. Schematic representation of SBCE IR steps. 


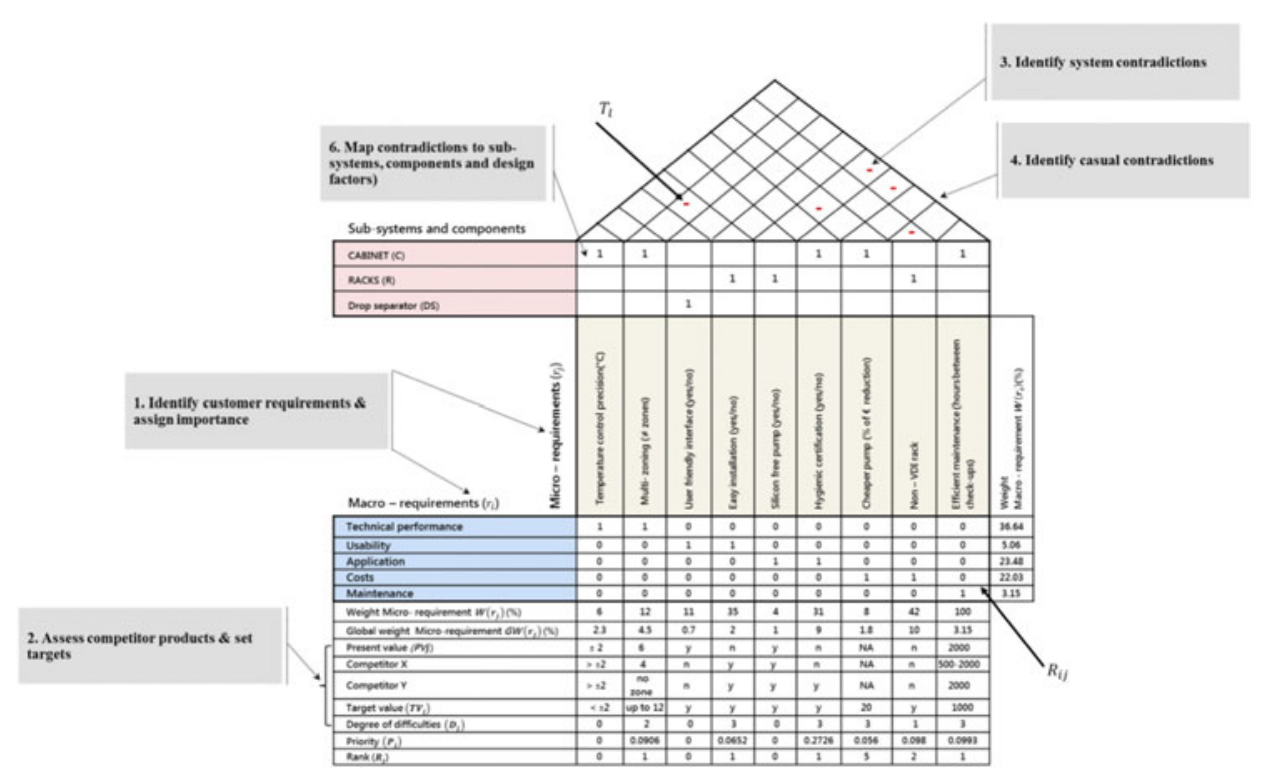

Figure 2. An example of HOQ and the steps to build the SBCE IR (excerpt from the AHS case study. Note: n, no; y, yes; NA, data not available).

process (AHP; Saaty, 1980) is used, which is based on pairwise comparison of requirements. AHP simplifies the understanding of customer requirements, avoids errors in judgment, and structures the evaluation of requirements from customer's perspective.

The relationships between the macro- and micro-requirements are given by a matrix $R_{i j}$, which indicates the categorization of micro-requirements into the respective classification of macro-requirements (see Figure 2). The relationship can take a value of either 0 or 1 ( 0 shows no relationship and 1 shows a relationship). This classification helps to represent customer data in a logical manner and simplifies data analyses. To obtain an aggregate global weight of a micro-requirement $\mathrm{GW}\left(r_{j}\right)$, the following equation is used (Yamashina et al., 2002):

$$
\left.\mathrm{GW}\left(r_{\mathrm{j}}\right)=W\left(r_{j}\right) \sum_{i=1}^{I} W\left(r_{i}\right) R_{i j}\right) .
$$

\section{Step 2: Assess competitors' products and set targets}

To assess competitors performances, three indicators are taken (Yamashina et al., 2002): present value $\left(\mathrm{PV}_{j}\right)$, which shows the current performance of a product for a particular micro-requirement $j$; target value $\left(\mathrm{TV}_{j}\right)$, which shows the desired performance of the product for a particular micro-requirement $j$ after an improvement has been made in the current design; and degree of difficulties $\left(D_{j}\right)$, which indicates the difficulties of achieving the gap between $\mathrm{PV}_{j}$ and $\mathrm{TV}_{j}$. Experts assign numeric values for $D_{j}$ considering the resource, know-how, and technology requirements to fill the gap (Yamashina et al., 2002). If the difference between $\mathrm{TV}_{j}$ and $\mathrm{PV}_{j}$ is negligible, then $D_{j}$ is set to be zero. This indicates that the product is already optimized in satisfying the requirement $j$. If the difference is considerable, then experts will assign a score for $D_{j}$ as shown in Equation (2): 


$$
\mathrm{D}_{\mathrm{j}}= \begin{cases}0 & \text { already achieved } \\ 1 & \text { easily achievable } \\ 2 & \text { moderately dificult to achieve } \\ 3 & \text { difficult to achieve }\end{cases}
$$

For example, looking the micro-requirement "Easy installation" in Figure 2, $\mathrm{PV}_{j}$ is "no" (i.e., the current design is difficult to install at customer sites) and the performance of the competitors' products $(X$ and $Y$ ) is “yes" (i.e., competitors' product are simple to install at customer sites). The designers in this case consider that improving the current design is important for competitiveness, and set $\mathrm{TV}_{j}$ as "yes." Moreover, improving the performance of the current design for the requirement is not a trivial design problem in terms of resource, know-how, and technology requirements, and the experts set $D_{j}=3$.

\section{Step 3: Identify system contradictions}

As discussed before, contradictions are potential areas, and overcoming them leads to the discovery of innovative design concepts. Experts can identify contradictions by studying the micro-requirements defined. If two requirements are in contradiction (technical contradiction), a negative sign (-) will be assigned on the roof of the HOQ (see Figure 2). For example, taking the AHS case study, there is technical contradiction between requirements "Multi-Zone and "Easy installation." Customers are requesting to have a humidifier that can cover up to 12 zones (i.e., to distribute and spray water mists to 12 different areas in a building or in an industrial establishment). At the same time, customers want to install the humidifier in a short period of time. The current design serves only 6 zones, and having 12 zones demands additional systems to be added into the product. Thus, more time is needed to install if a new product is designed for 12 zones.

Similarly, if a requirement is in contradiction with itself (physical contradiction), a negative sign (-) will be assigned on the roof of the HOQ (see Figure 2). Taking the AHS case study as an example, a requirement "non-VDI (Verein Deutscher Ingenieure) rack" is in contradiction with itself. The product should satisfy a European hygienic requirement called VDI 6022. However, once the company is expanding its business to different countries and sectors, VDI 6022 is not needed for some markets and applications (e.g., Tabaco industries and painting shops), and as a consequence the current design is expensive for these markets.

\section{Step 4: Identify causal contradictions}

In product system, contradictions identified in the previous step are not all independent (Mizuyama \& Ishida, 2007). There are casual relationships between contradictions. That is, solutions proposed to overcome certain contradictions alleviate other contradictions. If solutions feasible to solve a contradiction can overcome many other contradictions, then it would be efficient to take the root contradiction during prioritizing contradictions to pursue SBCE processes.

For example, consider the two contradictions in AHS case, contradiction $1\left(T_{1}\right)$ : "Multi-zone up to 12" versus "Modulation range" and contradiction $2\left(T_{2}\right)$ : "Modulation range" versus "Precision." 
$T_{1}$ implies that it is not possible to increase the zones (from the current 6 to the desired number of 12 zones) and at the same time increase the modulation range or the capacity of water flow (from the current range of $30-501 / \mathrm{h}$ to the desired range of $1-50 \mathrm{l} / \mathrm{h}$ ), because a pump used in the current design has limitation to do so. On the other hand, $T_{2}$ implies that it is not possible to increase the modulation range and at the same time achieve a desired level of precision in a short time. Precision for this particular case is defined as the percent of set point reached (set point is defined as the desired level of humidity level in a room). The desired precision level is reached through steps of increments. Thus, the contradiction $T_{2}$ indicates that when the range of modulation is extended to lower values, it takes more time to arrive into the desired precision level. However, the engineers claimed that if they design a new pump to overcome contradiction $T_{1}$, then contradiction $T_{2}$ is also automatically solved, and vice versa. Therefore, $T_{2}$ and $T_{1}$ have causal relationship.

However, as the number of contradictions in a product system grow, identifying such causal relationships are likely to be complicated. Moreover, there will be not only direct but also indirect causal relationships. Therefore, both direct and indirect relationships should be grasped and aggregated to identify causal relationships between contradictions. In this paper, Decision Making Trial and Evaluation Laboratory (DEMATEL) is the method that is used for this purpose (Fontela \& Gabus, 1974, 1978). The aim of DEMATEL is to identify the relationship between variables and use a matrix and causal diagram to express the casual relationships and influence level between variables in a complicated system. Four sub-steps are needed in DEMATEL:

(a) Define measurement scale and establish a direct-relation matrix

In order to define relationships between contradictions, experts will be asked to scale. The scale is used to identify how much of the problem in a contradiction ( $T_{l}, l=1,2,3 \ldots, m$, where $m$ is the number of contradictions identified) can be solved by overcoming another contradiction $\left(T_{k}, k=1,2,3 \ldots, m\right)$. A direct relationship matrix $X_{m \times m}$ can be defined as follows:

$$
X=\left[\begin{array}{cccc}
0 & x_{12} & \cdots & x_{1 m} \\
x_{21} & 0 & \cdots & x_{2 m} \\
\vdots & \vdots & \ddots & \vdots \\
x_{m 1} & x_{m 2} & \cdots & 0
\end{array}\right]
$$

The scale used in this paper is any value between 0 and 1 (where 0 indicates two contradictions are not related at all and 1 indicates there are completely related). For example, if $x_{l, k}=0$ (where $l, k \in m \& l \neq k$ ), then overcoming $T_{l}$ will not have any impact on solving $T_{k}$. If $x_{l, k}=1$ (where $l, k \in m$ ), then overcoming $T_{l}$ will completely solve $T_{k}$. The diagonal elements of matrix $X_{m \times m}$ are all set to zero.

(b) Calculate normalized direct-relation matrix

To normalize the matrix $X_{m \times m}$, its biggest sum of the row vector can be used as coefficient. The normalizing coefficient $\mu$ and the normalized matrix $N_{m \times m}$ can be determined as follows:

$$
\begin{gathered}
\mu=\frac{1}{\max _{1 \leq k \leq m}\left(\sum_{l=1}^{m} x_{l k}\right)}, \\
N=\mu X .
\end{gathered}
$$


(c) Direct/indirect-relation matrix

The direct/indirect-relation matrix shows the total relations between contradictions. For a contradiction, the matrix $\mp_{m \times m}$ that is determined using Equation (6) shows the total direct and indirect relations it has with other contradictions. As discussed before, contradictions might be solved by resolving other contradictions directly or indirectly.

$$
\mp=N(I-N)^{-1},
$$

where $I$ is an identity matrix of $m \times m$.

Now, set the elements $t_{l k}$ of the total matrix $¥$. The columns' and rows' sums of the total matrix $\mp$ can be determined using Equations (7) and (8), respectively. $D_{l}$ represents the total row sum of contradiction $T_{l}$, and indicates its total impact to other contradictions $T_{k}$. That is, the total contributions of design solutions proposed to overcome contradiction $T_{l}$ for other contradictions. $R_{l}$ represents the total column sum of contradiction $T_{l}$, and indicates the total impacts of other contradictions on $T_{l}$. That is, the total contributions of design solutions generated to resolve other contradictions on $T_{l}$.

$$
\begin{aligned}
& D_{l}=\sum_{k=1}^{m} t_{l k}(\text { where } l=1,2, \ldots, m), \\
& R_{l}=\sum_{l=1}^{m} t_{l k}(\text { where } k=1,2, \ldots, m) .
\end{aligned}
$$

(d) Draw out causal diagram

To visually depict complicated relationships of contradictions, causal diagram will be useful. Using Equations (7) and (8), define $\left(D_{l}+R_{l}\right)$ for $T_{l}$ as the prominence which shows the overall level of $T_{l}$ impact to and impacted by other contradictions. Then, define $\left(D_{l}-R_{l}\right)$ as the relationship, which shows the causal level of the contradiction. If this value is positive, then the contradiction is the cause, and solutions proposed to overcome it will also be solutions to solve other contradictions. If this value is negative, the contradiction is an effect, and solutions proposed to overcome other contradictions will solve the inherent contradiction in $T_{l}$. Furthermore, use $\left(D_{l}+R_{l}\right)$ as the transverse axis and $\left(D_{l}-R_{l}\right)$ as the longitudinal axis to construct causal diagram. It helps experts to easily identify those contradictions which are the root causes of other contradictions.

\section{Step 5: Derive rules to prioritize contradictions}

At this step, rules to prioritize contradictions for SBCE implementation are derived. From step 4, contradictions which have strong causal relationships can be identified. But, there are also contradictions which do not exhibit significant relationships. Thus, the two should be treated separately in deriving the rules. In this paper, contradictions which do not have strong causal relationships are called independent contradictions and those which exhibit strong causal relationships are called dependent contradictions.

(a) Prioritizing independent contradictions

Independent contradictions can be prioritized using the information in steps 1 and 2. Each contradiction has two information sources from its contradictory 
requirements: $\mathrm{GW}\left(r_{j}\right)$ and $D_{j}$. Thus, first these requirements can be prioritized and ranked. The priorities $\left(P_{j}\right)$ and ranks $\left(\operatorname{Rank}_{j}\right)$ of micro-requirements can be determined using Equations (9) and (10), respectively. Note, however, that Rank is determined taking micro-requirements within the same macro-requirement category. Moreover, the ranking in Equation (10) is in decreasing order except when it is zero (i.e., $\operatorname{Rank}_{j}=1>\operatorname{Rank}_{j}=2>\operatorname{Rank}_{j}=3 \cdots>\operatorname{Rank}_{j}=0$ ).

$$
\begin{gathered}
P_{j}=\mathrm{GW}\left(r_{j}\right) D_{j}, \\
\operatorname{Rank}_{j}=\left\{\begin{array}{ll}
1,2, \ldots n, & \text { if } P_{j} \neq 0 \\
0, & \text { if } P_{j}=0
\end{array} .\right.
\end{gathered}
$$

Using the Rank $\mathrm{j}_{j}$ values, independent contradictions can be prioritized. There are two possible cases: domination and tie. In the domination case, a dominating contradiction has higher rankings in both of it contradictory requirements than a dominated one. But, in the tie case, a contradiction neither dominates nor dominated by another contradiction in the ranking of its contradictory requirements. For example, let us take four contradictions $T_{1}, T_{2}, T_{3}$, and $T_{4}$ with the rankings of the corresponding contradictory requirements as $(1,1),(1,2),(1,4)$, and $(2,1)$ respectively. $T_{1}$ dominates all contradictions, $T_{2}$ dominates $T_{3}$, but both $T_{2}$ and $T_{3}$ are in tie with $T_{4}$. Thus, when designers have to choose between contradictions to pursue SBCE, dominating contradictions will have higher priorities. But, in the case of tie, experts' judgments should be used taking other criteria such as resource required, availability of know-how, and technology for prioritization.

(b) Prioritizing dependent contradictions

Prioritizing based on the ranking method introduced above might not be efficient for contradictions that have strong causal relations. Let us take the example given above, and suppose in step 4 of SBCE IR the causal relations between the four contradictions are found to be as shown in Figure 3. The relationships that are shown in the figure can be interpreted as follows: overcoming $T_{3}$ directly overcomes $T_{2}$ and $T_{4}$, and overcoming $T_{3}$ indirectly overcomes $T_{1}$ through $T_{2}$. Moreover, assume that all the causal relations (direct and indirect) are strong (i.e., overcoming $T_{3}$ certainly overcomes $T_{2}$ and $T_{4}$ directly, and overcoming $T_{3}$ certainly overcomes $T_{1}$ indirectly). ${ }^{5}$ In such circumstances, although $T_{1}$ dominates all contradictions based on its ranking, giving priority to the root contradiction $T_{3}$ is efficient. This means that solutions proposed to overcome $T_{3}$ will certainty overcome the effect contradictions $\left(T_{1}, T_{1}\right.$, and $\left.T_{1}\right)$. As a result, more innovation can be achieved by overcoming the root contradiction.

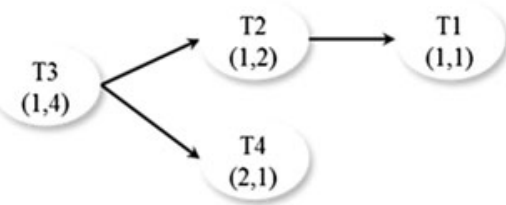

Figure 3. Example of casual relationships between $T_{1}, T_{2}, T_{3}$, and $T_{4}$. Note: The arrows show casual relations between the contradictions. The values in the parentheses show the rankings. 
One might argue that the above argument might be misleading if overcoming a root contradiction needs more resources or the know-how and technology required are not available. This is a valid argument, and in this situation additional experts' assessments are needed to prioritize dependent contradictions. On the other hand, this paper makes a logical assumption that, contradictions that exhibit strong causal relations are technically highly related, and have similar resources or know-how or technology requirements - thus selecting root contradiction is more efficient. Even if this assumption does not hold, knowing the causal relationships of dependent contradictions facilitate discussion among experts to make efficient and rational choices among contradictions.

In summary, in order to make priorities between contradictions, three rules are derived for the three possible scenarios explained before. Scenario 1 is for independent contradictions, and when there is a dominating contradiction. Scenario 2 is for independent contradictions, and when there is a tie between contradictions. Scenario 3 is for dependent contradictions, and when there is a root contradiction having strong relations with effect contradictions. The selection rules are shown in Equation (11).

$$
\text { Select } \sim\left\{\begin{array}{l}
\text { dominating contradiction in scenario } 1 \\
\text { based on experts jugment in scenario } 2 \\
\text { root contradiction in scenario } 3
\end{array}\right.
$$

\section{Step 6: Map contradictions to products' design factors and begin SBCE process}

Once contradictions are prioritized, designers at this step map selected contradictions to design factors. This step is aimed to identify what design factors (e.g., material type, dimensions, and number of components used) that can possibly be changed in the current design to overcome a contradiction. Once mapping is finished, SBCE process can be started to explore, communicate, test, and converge sets of solutions proposed to overcome the selected contradiction. That means, the selected contradiction with the design factors will be input to begin an SBCE process.

\section{Case study on AHS}

AHS is used for different applications (such as hospitals, residential buildings, textile factories, and paint shops in car industries). The main function of the system is to control temperature and humidity levels of an ambient. The working principle is based on spraying atomized water mists to air at high pressure (around 70 bars) whenever the temperature and humidification levels are not desirable. Three basic subsystems are shown in Figure 4. Cabinet (C) is used as a control and pumping station. Rack (R) is used as a distribution center. Drop Separator (DS) is used to filter water content.

AHS is a complex product and involves several subsystems, components, and associated design factors. There are several requirements associated with this product related to technical, market, and business issues. As a result, several interrelated contradictions are expected in the system. Moreover, AHS has been in the market for the last 10 years and few improvement projects have launched in the past years. Therefore, this case study has been selected to demonstrate the applicability of SBCE IR methodology and to plan improvement areas where SBCE can be applied. 


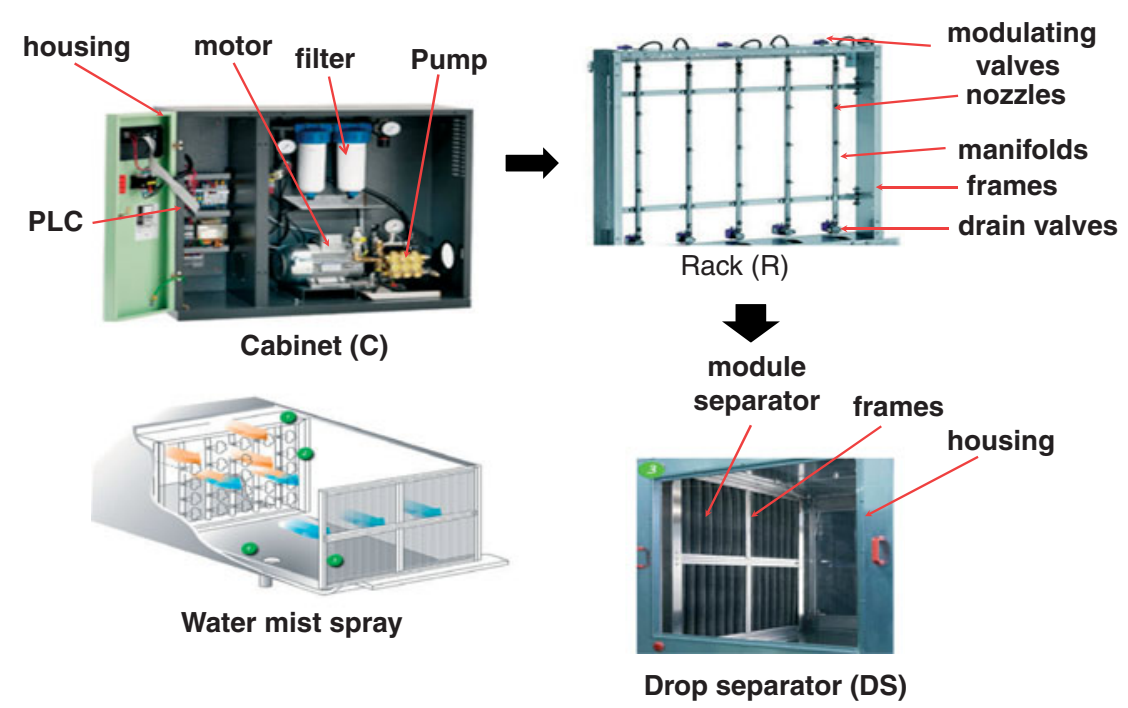

Figure 4. AHS system, subsystems, and components.

\section{Step 1: Identify customer requirements and assign importance}

AHS experts conducted extensive study using phone calls and visiting customers to identify real customer requirements. Internal discussions with upper management and marketing were held to identify new and emerging requirements that customers are not able to identify.

Five macro-requirements are identified: (1) Technical performance $(\mathrm{P})$, which is related to the technical quality characteristics that the product should satisfy; (2) Usability (U), which is related to the product's simplicity during installation and use; (3) Application (A), which is related to the flexibility of the system to be used in different applications (e.g., paint shop, data centers, and hospitals); (4) Costs (C), which is aimed at minimizing the cost of the system; and (5) Maintenance (M), which is aimed to achieve easy repair of components and reduce time between check-ups.

For each of the five macro-requirements, specific micro-requirements are defined. For $\mathrm{P}, \mathrm{U}, \mathrm{A}, \mathrm{C}$, and $\mathrm{M}$, there are $11,4,5,5$, and 1 micro-requirements identified, respectively (see Figure 5). For example, for Usability (U), the micro-requirements are as follows: U1 (Wide option range), to have a user interface in different languages and make the product to operate wider operations during user-product interactions; U2 (Integration to customers' air-handling units, AHUs), to enable the product to fit into customers sites; U3 (Easy installation), to reduce the time to install the product at the customers sites; and U4 (Friendly user interface), to simplify the user experience during customer-user interactions.

Experts assign judgment matrices for the macro- and micro-requirements. The elements of the matrices show the importance between requirements within the scales defined $(1 / 9,1 / 8, . . ., 8,9)$ (Saaty, 1980). For example, Table 2 shows the judgment matrix assigned for macro-requirements and Table 3 shows the judgment matrix assigned for micro-requirements categorized in the $\mathrm{U}$ macro-requirement. Similarly, judgment matrices are made for all other micro-requirements. Looking at the judgment matrices, the importance of a requirement over the others can be understood. For instance, looking at 


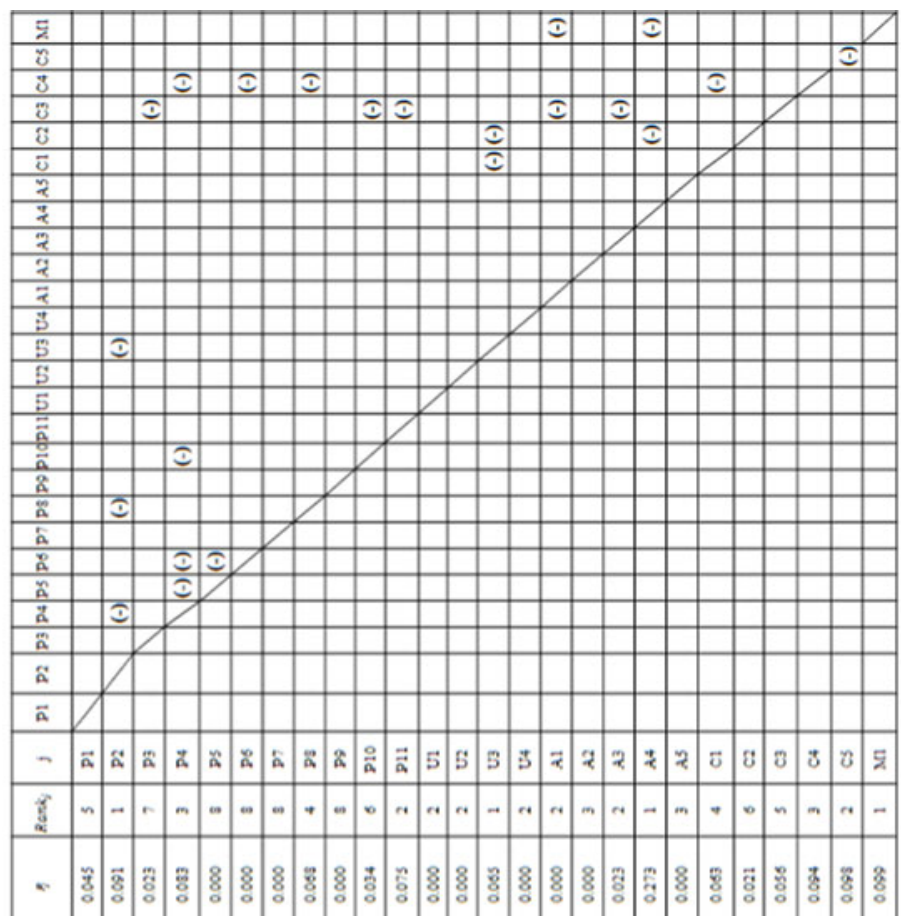

\begin{tabular}{|c|c|c|c|c|c|c|c|c|c|c|c|c|c|c|c|c|c|c|c|c|c|c|c|c|}
\hline$y$ & E & 基 & $\therefore$ & 远 & $\frac{8}{2}$ & कै & कै & ถิ) & ติ & y & $\frac{1}{4}$ & & \% & 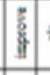 & कै के & $\gamma$ \% & $=1$ & 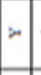 & & & 8 & & . & 8 \\
\hline 竞: & $\mathrm{E}$ & 㖏 & $\bullet$ & $z$ & 98 & - & 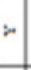 & 昌 & $\ddot{A}$ & r & 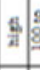 & & :- & \% & $\Rightarrow x$ & $\Rightarrow$ & $=1$ & $\%$ & $-\infty$ & ह5 & 量 & it & z & \\
\hline 8 & f. & s. & - & ⿶凵 & gas & 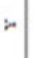 & 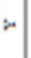 & 苅 & 2 & $m$ & 3 & & $\%$ & 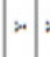 & $\Rightarrow x$ & $-x$ & $\approx$ & $\%$ & 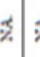 & 5.3 & 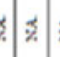 & 3. & $\%$ & $\frac{x}{2}$ \\
\hline i & 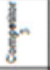 & 专 & & $\frac{x}{2}$ & 28 & - & $;$ & $\xi$ & 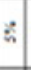 & 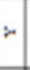 & s. & & $=$ & $\Rightarrow$ & $\therefore z$ & $\%$ & $\approx$ & $\%$ & $\%$ & 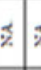 & 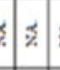 & 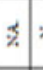 & $\%$ 通 & \\
\hline 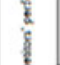 & 8 & 悬. & - & $\frac{x}{2}$ & 28 & ;- & 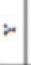 & 官 & s. & 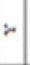 & $\mathrm{g}$ & ; & $=$ & z & $\therefore=$ & 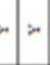 & 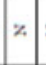 & $z$ & ; & 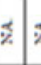 & 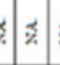 & $\frac{5}{2}$ & $z \mid \frac{5}{8}$ & \\
\hline & $f$ & 至 & + & $\frac{x}{2}$ & 98 & $\therefore$ & - & 兽 & 4 & 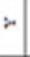 & $\underline{5}$ & & 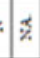 & 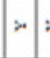 & $\Rightarrow 2$ & 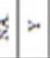 & 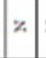 & $\%$ & 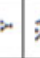 & 3. & $\tilde{z}$ & 3 & $\%$ & 융 \\
\hline & 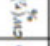 & c. & $\sim$ & - & 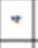 & 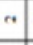 & $m$ & $\circ$ & $m$ & ? & m. &.+ &.- & $\therefore$. & $-\quad-$ & -0 & - & a & $\approx$ & $\therefore-$ & $\begin{array}{lll}0 . \\
\end{array}$ & $n$ & 인 & $m$ \\
\hline & $\widehat{E}$ & $\circ$ & $\approx$ &. & $=$ & $\circ$ & $\therefore$ & - & a. & $\therefore$ & ${ }^{\circ}$ & $9=$ & 2 & $\approx=$ & $\Rightarrow$. & $+\vec{\pi}$ & $\cdot$ & $\vec{m}$ & $\%:$ & $\therefore-$ & $=$ & 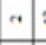 & 7 & 8 \\
\hline & 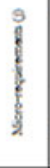 & $\begin{array}{l}0 \\
8 \\
8 \\
8\end{array}$ & 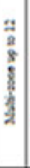 & $\begin{array}{l}8 \\
\frac{1}{4} \\
\frac{1}{3}\end{array}$ & 章 & & $\begin{array}{c}3 \\
\vdots \\
3\end{array}$ & ถ̊ & $\begin{array}{l}\frac{5}{2} \\
\frac{8}{8} \\
8 \\
8\end{array}$ & 8 & 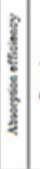 & 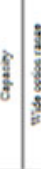 & : & $\begin{array}{l}\frac{1}{3} \\
\frac{1}{3}\end{array}$ & 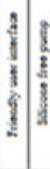 & $\frac{1}{2}$ & 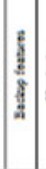 & 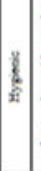 & 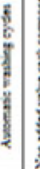 & & 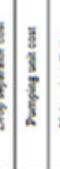 & $\frac{1}{3}$ & 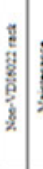 & \\
\hline & - & $\vec{\alpha}$ & $\approx$ & $\approx$ & से & ळे & $\approx$ & 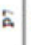 & 券 & 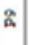 & $\vec{\alpha}$ & $\overrightarrow{\vec{a}} 5$ & 5 & $3:$ & $5=$ & $\bar{x} q$ & ₹ & 7 & $₹$ & एक & 3 & 3 & 3 & $\bar{E}$ \\
\hline & & & & & & & DE & & & & & & & & & & $6 z$ & & & & $5 z$ & & & $\varepsilon$ \\
\hline & & & & & 1) 25 & a & $y=d$ & Fon & 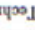 & & & & & IItq & & (v) $\times$ & offuexy & $n d d y$ & & & (D) 11000 & & & \\
\hline
\end{tabular}

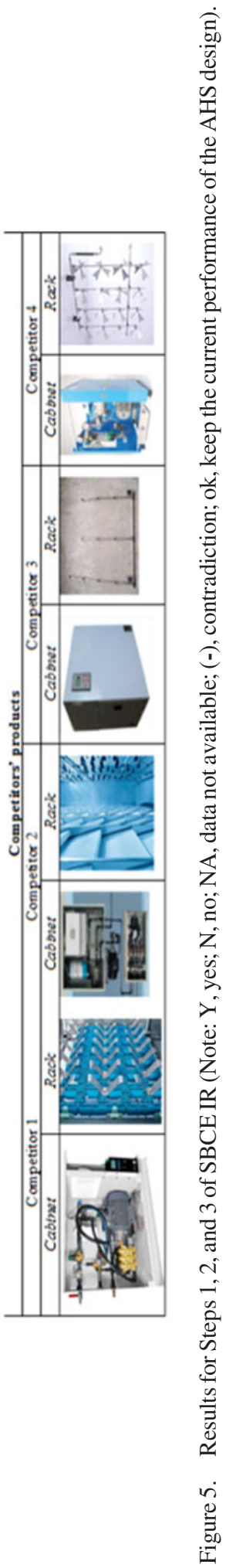


Table 2. Judgment matrix for the macro-requirements.

\begin{tabular}{lccccc}
\hline & $\mathrm{P}$ & $\mathrm{U}$ & $\mathrm{A}$ & $\mathrm{C}$ & $\mathrm{M}$ \\
\hline Performance (P) & 1 & 5 & 1 & 3 & 9 \\
Usability (U) & $1 / 5$ & 1 & $1 / 7$ & $1 / 5$ & 3 \\
Application (A) & 1 & 7 & 1 & 1 & 6 \\
Costs (C) & $1 / 3$ & 5 & 1 & 1 & 8 \\
Maintenance (M) & $1 / 9$ & $1 / 3$ & $1 / 6$ & $1 / 8$ & 1 \\
\hline
\end{tabular}

Table 2, $\mathrm{P}$ is five times more importance than $\mathrm{U}$, same importance as $\mathrm{A}$, three times important than $\mathrm{C}$, and nine times important than $\mathrm{M}$.

Using AHP method, the weight vectors $W\left(r_{i}\right)$ and $W\left(r_{i}\right)$ are determined as shown in Figure 5. The weight vectors are iteratively obtained till consistency is guaranteed (Forman, 1990; Saaty, 1980). In AHS system, P, A, and C macro-requirements have the highest importance with weights $37 \%, 29 \%$, and $24 \%$, respectively. Moreover, $\mathrm{GW}\left(r_{j}\right)$ is calculated using Equation (1) (see Figure 5). From cost (C) category, for example, "nonVDI rack" requirement has the highest global weight of $10 \%$.

\section{Step 2: Assess competitors' products and set targets}

Four competitors' products are selected. To set targets for improvement and to determine $D_{j}$ values, the performances of competitors' designs are evaluated by the AHS experts for each micro-requirement. Looking at Figure 5, for example, P2 "Multi-zone" is the number of zones the product has to serve. The number of zones the competitors' product serve ranges from 1 to 4 , and the current design of the AHS serves only 6 zones $\left(\mathrm{PV}_{P 2}=6\right)$. However, it is targeted to have 12 numbers of zones $\left(\mathrm{TV}_{P 2}=12\right)$. Using Equation (2), the designers set the $D_{P 2}$ as 2 as it is moderately difficult to change the current design technology. On the other hand, looking at C5 "Non-VDI6022 rack," the competitors' products do not satisfy this hygienic requirement. Neither does the case product $\left(\mathrm{PV}_{C 5}=\right.$ $N$ ), but as there is emerging markets looking for a cheaper non-VDI rack version, designers set the target as "yes" $\left(\mathrm{TV}_{C 5}=Y\right)$ and $D_{C 5}$ as 2 .

\section{Step 3: Identify system contradictions}

Twenty-two technical contradictions and one physical contradiction are identified as shown in Figure 5 and Table 4. As seen from the result, six of the contradictions $\left(T_{1}-T_{6}\right)$ are between technical requirements (Ps), and the rest are either between technical requirements and business-related requirements (Usability, Application, and Costs) or between businesses-related requirements. This shows that the current AHS design is highly optimized for technical performances but need significant innovation to maximize

Table 3. Judgment matrix for the usability (U) micro-requirements.

\begin{tabular}{lcccc}
\hline & $\mathrm{U} 1$ & $\mathrm{U} 2$ & $\mathrm{U} 3$ & $\mathrm{U} 4$ \\
\hline Wide option range (U1) & 1 & 2 & 1 & 3 \\
Integration on AHU (U2) & $1 / 2$ & 1 & $1 / 2$ & 2 \\
Easy installation (U3) & 1 & 2 & 1 & 3 \\
Friendly user interface (U4) & $1 / 3$ & $1 / 2$ & $1 / 3$ & 1 \\
\hline
\end{tabular}


Table 4. Contradictions and the respective contradictory requirements.

\begin{tabular}{lcccccccccccc}
\hline Contradictions & $T_{1}$ & $T_{2}$ & $T_{3}$ & $T_{4}$ & $T_{5}$ & $T_{6}$ & $T_{7}$ & $T_{8}$ & $T_{9}$ & $T_{10}$ & & \\
\hline$r_{\text {up }}$ & P2 & P4 & P4 & P5 & P2 & P4 & P2 & U3 & U3 & A4 & & \\
$r_{\text {down }}$ & P4 & P5 & P6 & P6 & P8 & P10 & U3 & C1 & C2 & C2 & & \\
\hline$T_{11}$ & $T_{12}$ & $T_{13}$ & $T_{14}$ & $T_{15}$ & $T_{16}$ & $T_{17}$ & $T_{18}$ & $T_{19}$ & $T_{20}$ & $T_{21}$ & $T_{22}$ & $T_{23}$ \\
\hline P3 & P10 & P11 & A1 & A3 & P4 & P6 & P8 & A4 & C1 & C5 & A1 & A4 \\
C3 & C3 & C3 & C3 & C3 & C4 & C4 & C4 & C4 & C4 & C5 & M1 & M1 \\
\hline
\end{tabular}

Note: up, down $\in j$

business-related performances. And, each contradiction is a potential input to SBCE process (refer to Section 3.2, step 3 for the detail explanations of contradictions $T_{7}$ and $T_{21}$ ).

\section{Step 4: Identify causal contradictions}

Using Equation (3) of DEMATEL, designers scale the direct relationships between contradictions using a scale from 0 to 1 as shown in Table 5. For example, the relationship between $T_{2}$ and $T_{1}$ is scaled as $1\left(x_{21}=1\right)$, implying that overcoming $T_{2}$ completely resolve $T_{1}$ (see Section 3.2, step 4 for detail discussion on this example).

However, the relations between contradictions are not only direct but also include indirect relations. For example, solving contradiction $T_{2}$ can solve the inherent contradiction in $T_{1}\left(x_{21}=1\right)$. Moreover, solving $T_{1}$ also solves the inherent contradiction in T6 $\left(x_{16}=1\right)$. From transitivity, it means that solving $T_{2}$ solves indirectly contradiction $T_{6}$. Thus, the total direct and indirect relationship matrix $\mathrm{F}$ explains such relations. Using Equation (6), $\mp$ is calculated as shown in Table 6 (the normalizing coefficient $\mu$ is calculated as 1/5.8 using Equation (3)). Taking $T_{2}$ as an example from the matrix $\mp$, it can be seen that its total impact on other contradictions can be read from the matrix. Solving contradiction $T_{2}$ means that there are chances of $0.28,0.08,0.08,0.16,0.23$, and 0.22 of solving $T_{1}, T_{2}, T_{3}, T_{4}, T_{5}$, and $T_{6}$, respectively.

Now, the column $(D)$ and the row $(R)$ sums of matrix $\mp$ can be calculated using Equations (7) and (8). $D$ indicates the total impact of a contradiction over others. $R$ indicates the influences of others on a contradiction. For example, $D\left(T_{2}\right)=0.06+0.08+$ $\cdots+0=1.19$, and $R\left(T_{2}\right)=0.28+0.08+0.08+0.16+0.23+0.22+0.00+\cdots$ $+0.00=1.05$. The $D$ and $R$ values of each contradiction are determined as shown in Table 7.

The sum $D+R$ shows the total connections of a contradiction with other contradictions in the AHS system. The higher this value, the higher interaction a contradiction has with others. The difference $D-R$ shows the cause or the effect behavior of a contradiction. A higher negative value for a contradiction implies an effect and a lower negative value shows a cause. For example, looking the $D-R$ values of $T_{1}(-1.28)$ and $T_{2}(-0.14)$ in Table 7, $T_{2}$ behaves more as a cause and $T_{1}$ behaves as an effect. Thus, overcoming $T_{2}$ provides solutions for more other contradictions and solutions proposed for other contradictions eventually overcome $T_{1}$.

Taking the averages of $D+R=1.12$ and $D-R=0$ as vertical and horizontal axes, respectively, the causal diagram can be drawn as shown in Figure 6. As it is shown in the figure, except the contradictions $T_{1}, T_{2}, T_{3}, T_{4}, T_{5}$, and $T_{6}$, all the other contradictions $\left(T_{7}-\right.$ $T_{21}$ ) have prominence values $(D+R)$ below the average (1.12). This result implies that contradictions from $T_{7}$ to $T_{21}$ do not have considerable interrelationships between other 


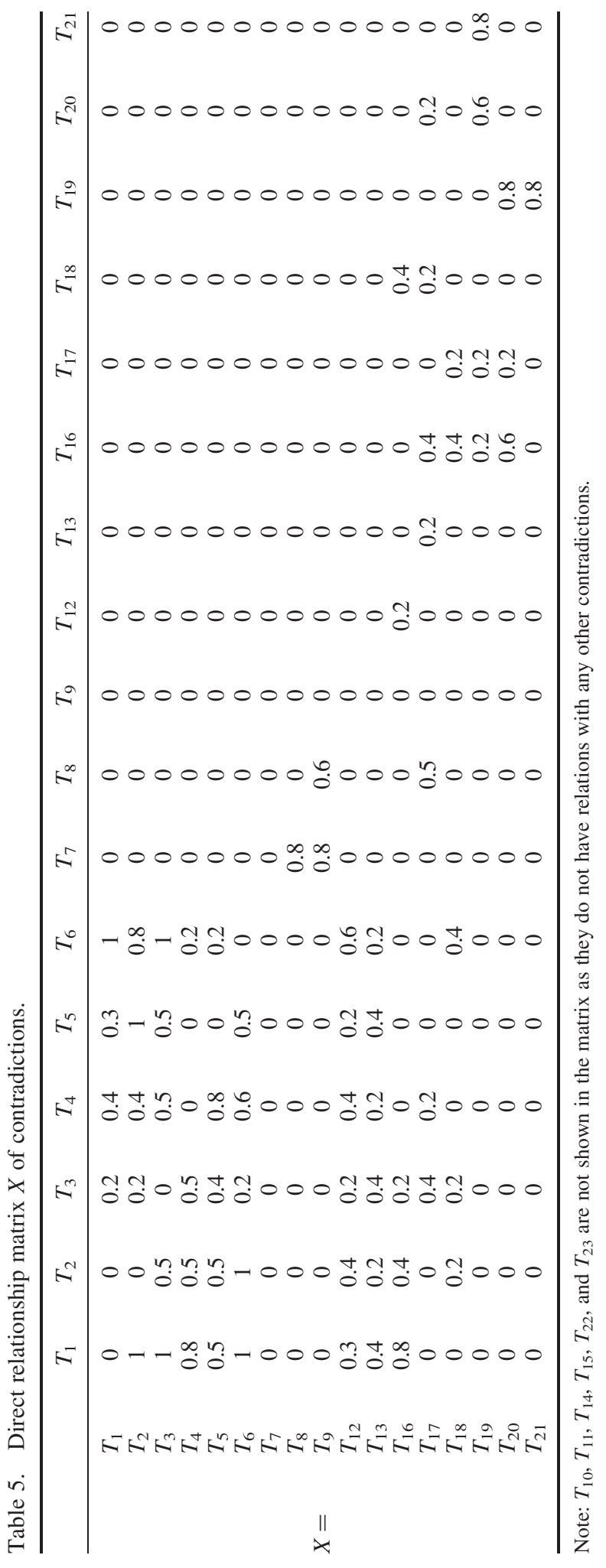




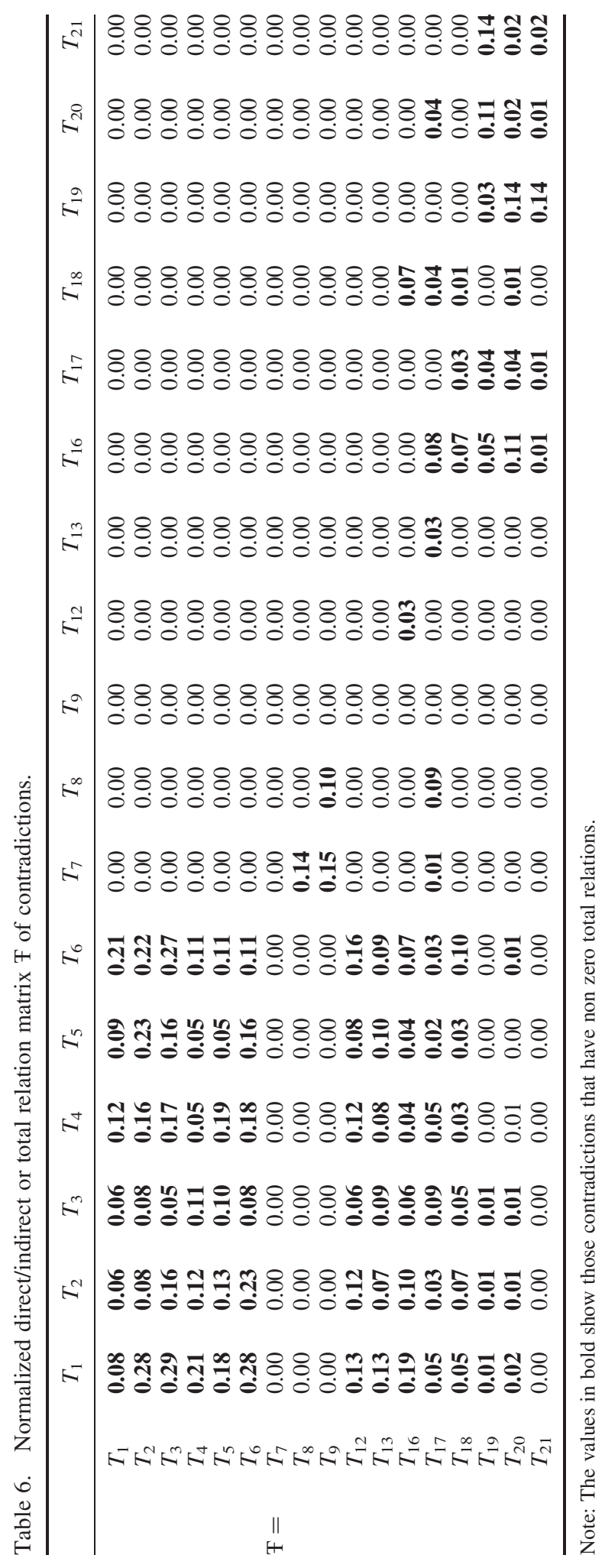


Table 7. Causal influence level of contradictions.

\begin{tabular}{lcccc}
\hline Contradictions & $D$ & $R$ & $D+R$ & $D-R$ \\
\hline$T_{1}$ & 0.63 & 1.91 & 2.54 & -1.28 \\
$T_{2}$ & 1.05 & 1.19 & 2.24 & -0.14 \\
$T_{3}$ & 1.10 & 0.86 & 1.96 & 0.24 \\
$T_{4}$ & 0.65 & 1.19 & 1.85 & -0.54 \\
$T_{5}$ & 0.76 & 1.01 & 1.77 & -0.25 \\
$T_{6}$ & 1.03 & 1.49 & 2.52 & -0.46 \\
$T_{7}$ & 0.00 & 0.30 & 0.30 & -0.30 \\
$T_{8}$ & 0.14 & 0.20 & 0.34 & -0.06 \\
$T_{9}$ & 0.26 & 0.00 & 0.26 & 0.26 \\
$T_{12}$ & 0.68 & 0.05 & 0.73 & 0.64 \\
$T_{13}$ & 0.58 & 0.04 & 0.61 & 0.54 \\
$T_{16}$ & 0.60 & 0.32 & 0.92 & 0.27 \\
$T_{17}$ & 0.56 & 0.13 & 0.69 & 0.44 \\
$T_{18}$ & 0.45 & 0.13 & 0.58 & 0.32 \\
$T_{19}$ & 0.42 & 0.33 & 0.75 & 0.09 \\
$T_{20}$ & 0.41 & 0.18 & 0.59 & 0.01 \\
$T_{21}$ & 0.20 & 0.18 & 0.38 & 0 \\
Average & & & 1.12 & \\
\hline
\end{tabular}

contradictions in the system, and can be considered as independent contradictions. However, contradictions $T_{1}-T_{6}$ have considerable interrelationships, and can be considered as dependent contradictions.

Drawing all the relationships between the dependent contradictions is too complex, and it will be difficult to visualize important relationships. Thus, a threshold of 0.2 in $\mathrm{F}$ matrix is considered to filter strong relations (Lee, Li, Yen,\& Huang, 2010). That is, cutting all weak relations in $\mathrm{F}$ matrix as shown in Table 8.

\section{Step 5: Derive rules to select contradictions to start SBCE processes}

From step 4, it has been possible to identify the causal relationships between contradictions and separate dependent and independent contradictions. Contradictions

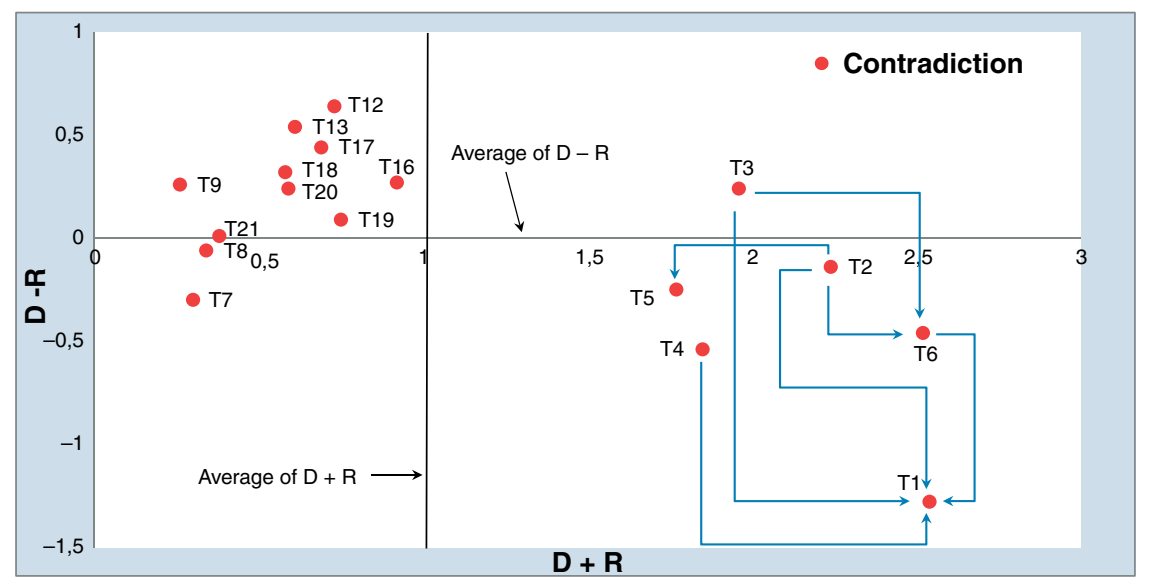

Figure 6. DEMTEL causal relations diagram between contradictions in AHS. 
Table 8. Normalized direct/indirect or total relation matrix $\mathrm{F}_{\mathrm{Cut}=20 \%}$.

\begin{tabular}{cccccccc}
\hline & $T_{1}$ & $T_{2}$ & $T_{3}$ & $T_{4}$ & $T_{5}$ & $T_{6}$ \\
\hline & $T_{1}$ & & & & & & 0.21 \\
$\mathrm{~F}_{\mathrm{Cut}=20 \%}$ & $T_{2}$ & 0.28 & & & & & 0.23 \\
& $T_{3}$ & 0.29 & & & & & \\
& $T_{4}$ & 0.21 & & & & \\
& $T_{5}$ & & & & & & \\
& $T_{6}$ & 0.28 & 0.23 & & & & \\
\hline
\end{tabular}

$T_{1}-T_{6}$ are dependent and the rest $T_{7}-T_{23}$ are independent contradictions. Referring Equation (11), the dependent contradictions can be prioritized taking the root cause contradictions and independent contradictions are prioritized using the rankings of the corresponding contradictory requirements.

Using the ${ }_{\mathrm{FCut}}=0.2$ matrix shown in Table 8 and the causal diagram in Figure 6, the causal relations between dependent contradictions are shown in Figure 7. For example, contradiction $T_{2}$ is the root for $T_{5}, T_{6}$, and $T_{1}$, therefore, designers should give priority for $T_{2}$ to be overcome. Although $T_{2}$ is in tie in ranking with $T_{5}$, dominated by $T_{1}$ and $T_{6}$, starting SBCE process for $T_{2}$ will provide solutions for $T_{2}, T_{5}, T_{6}$, and $T_{1}$ simultaneously. Consequently, more numbers of innovations can be obtained by focusing on the roots than on the causes. However, as previously discussed in Section 3.2, step 5, this conclusion is assuming that the effort, the know-how, and technology required to overcome the roots are reasonably similar to the causes. Otherwise, experts should use the causal relationships to discuss on which contradictions the SBCE effort will have to focus on by adding other criteria.

For independent contradictions, prioritizing is based on the ranking of the contradictory micro-requirements $\left(\operatorname{Rank}_{j}\right)$ calculated using Equation (10). Figure 8 shows the independent contradictions and the rankings of the contradictory requirements. Looking at Figure 8, it is possible to identify dominating and tie contradictions in which prioritizing rules listed in Equation (11) can be used to select contradictions for further SBCE implementations.

Taking $T_{21}$ as example, it is dominated by $T_{7}$ and $T_{23}$, it is in tie with $T_{8}, T_{9}, T_{10}$, and $T_{19}$, and it dominates all the rest of independent contradictions as shown in Figure 8. If designers are conformed to choose between $T_{21}$ and its dominating contradictions, using

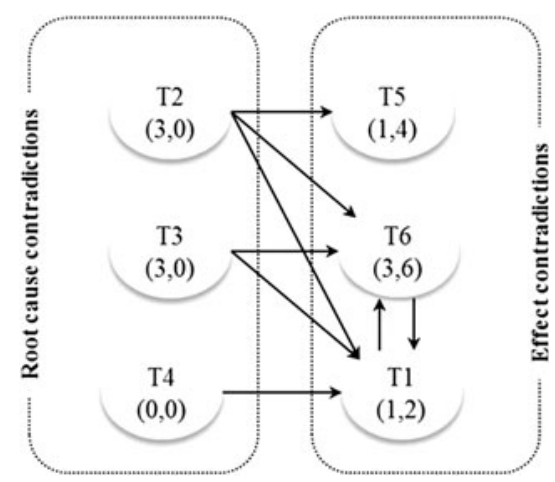

Figure 7. Causal relations of dependent contradictions. 


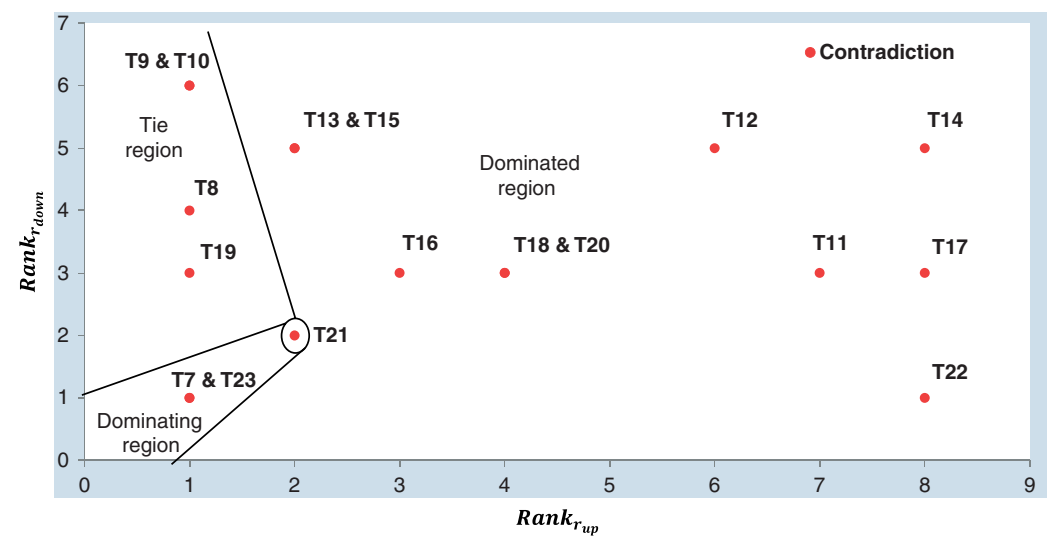

Figure 8. Independent contradictions and the rankings of corresponding contradictory requirements.

the rules listed in Equation (11), efforts should be made to overcome $T_{7}$ and $T_{23}$ before $T_{21}$. On the other hand, $T_{21}$ should be selected for SBCE implementation before any contradictions that it dominates. Moreover, experts have to impose other criteria other than customer importance and competiveness to select between $T_{21}$ and contradictions that are in tie with it. These criteria could be resources and capabilities available in PD that are necessary to overcome the contradictions. Here, as the company is sourcing most of its components from suppliers, the capabilities are not limited to internal suppliers but also include the external suppliers. If suppliers' technologies are not ready to make innovative solutions to overcome certain contradictions, experts should evaluate these kinds of aspects into consideration during prioritizing contradictions. Nevertheless, these considerations are not limited to prioritize tie contradictions. If solving a dominating contradiction exceeds existing technological capabilities, experts might focus on a dominated one even if it is less of a priority to delight customers and achieve competitive advantages.

In summary, most contradictions are potential areas for improvement. Some contradictions need considerable time to pursue SBCE process and some need less time. However, using Figures 7 and 8, the experts will have a rough understanding of which contradictions to target, and can plan SBCE processes to offer innovative AHS in short or long terms.

\section{Step 6: Map contradictions to products' design factors}

At this step of the SBCE IR, designers are asked what design factors need to be changed for selected contradictions. The experts involved were asked to select a contradiction that can be a good candidate for SBCE process experimentation. Considering the time available during the preparation of this study, contradiction $T_{21}$ is selected though it is dominated by some $\left(T_{7}\right.$ and $\left.T_{23}\right)$ and it is in tie with $T_{8}, T_{9}, T_{10}$, and 19.

$T_{21}$ is a physical contradiction of the requirement C5 "non-VDI rack." The current AHS design which is VDI6022 compliant is overly designed for growing number of markets (e.g., Tabaco industries and painting shops of automotive industries). These customers are requiring cheaper design and there are nonvalue-adding features in the current system. However, the product has to satisfy the VDI6022 requirement for other 


\begin{tabular}{|c|c|c|c|}
\hline \multicolumn{4}{|c|}{$\begin{array}{l}\begin{array}{l}\text { Mapping contradiction 'non-VDI rack' to rack design } \\
\text { factors }\end{array}\end{array}$} \\
\hline \multicolumn{2}{|c|}{ Components } & Functions & Design factors \\
\hline $\begin{array}{l}\neq 1 \\
\neq 7\end{array}$ & $\begin{array}{l}\text { Frame and } \\
\text { bracket }\end{array}$ & $\begin{array}{l}\text { Support and } \\
\text { simplify cleaning } \\
\text { operations }\end{array}$ & $\begin{array}{l}\text { Number of frames and } \\
\text { brackets }\end{array}$ \\
\hline$\neq 4$ & $\begin{array}{l}\text { Modulating } \\
\text { valve }\end{array}$ & Modulate & $\begin{array}{l}\text { Number of valves for a } \\
\text { manifold }\end{array}$ \\
\hline$\neq 5$ & Flexible hose & $\begin{array}{l}\text { Transfer high } \\
\text { pressure water }\end{array}$ & Number of hoses \\
\hline$\neq 9$ & Drain valve & Drain water & Material types of drain valve \\
\hline$\neq 6$ & $\begin{array}{l}\text { Holes and } \\
\text { cups on } \\
\text { manifold }\end{array}$ & $\begin{array}{l}\text { Simplify cleaning } \\
\text { operations }\end{array}$ & $\begin{array}{l}\text { Number of holes and cups to } \\
\text { use }\end{array}$ \\
\hline
\end{tabular}

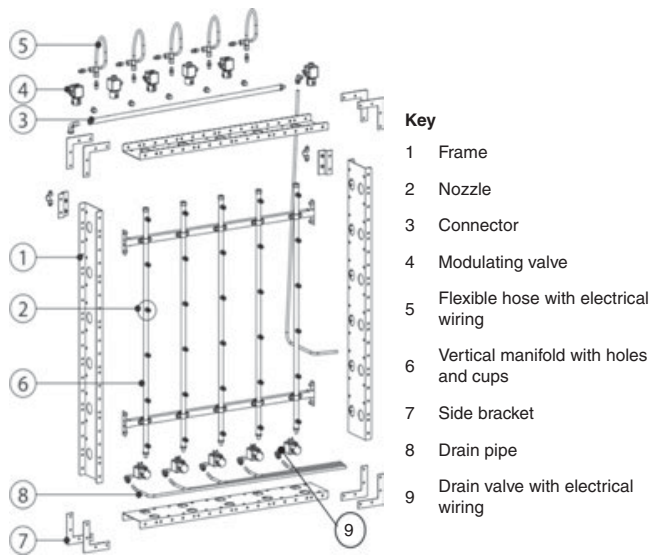

Figure 9. An example of mapping contradiction T21 to rack design factors.

markets at the same time. Thus, the purpose of overcoming the contradiction is to satisfy both types of customers.

In order to find solutions in this step, the experts need to map the design factors that have to be the targets. Figure 9 shows the components and their design factors that are candidate for SBCE process to overcome $T_{21}$. In this case, rack components are identified which have excess features that cause the contradictions. For example, the material type of the drain valve used in the current AHS design is considered as one of the design factors that need to be investigated to eliminate the contradiction. In Section 5, the SBCE process conducted to eliminate $T_{21}$ is discussed.

\section{SBCE process on rack subsystem}

The simplified working principle of the rack subsystem is as follows: highly pressurized water (about 70 bar) will be pumped from the pumping units (motor and pump, see Figure 4 ) to the solenoid modulating valves which are normally closed (see Figure 9, $\neq 4$ ). These valves pass the modulated water to the rack distribution system. Because the water pressure inside the rack will increase to a desired level step by step, the modulating solenoid valves are connected with each other using flexible hoses (i.e., when the water reaches the last manifold column, the desired pressure will achieved). Then, the water passes through the vertical manifolds (see Figure $9, \neq 6$ ) and sprayed out to a room through nozzles (see Figure 9, $\neq 2$ ). Empty holes which are used to clean the rack will be covered by cubs (see Figure $9, \neq 6$ ). Finally, once the rack finishes operation, the water leaves the rack distribution system through the solenoid drain valves (see Figure $9, \neq 9$ ).

\subsection{Exploration of alternative concepts}

Before exploring alternative rack concepts to overcome $T_{21}$, the prevalent TRIZ principle of separation is agreed by the company to be adopted (Altshuller, 1984, 1994, 1999). This means the company will offer two different rack versions to two different markets. The first version is complaint with VDI6022 requirement (which is the current rack design), the other and the new rack will be a non-VDI6022 rack version. Thus, the concepts generation effort focuses on eliminating nonvalue-adding features on the current design that are not needed by the non-VDI customers. 
After brainstorming on several sessions, designers explore four different concepts for the new rack version: (a) frameless rack, (b) changing the solenoid stainless-steel drain valves to mechanical brass valves, (c) using one solenoid modulating valve for two manifolds, and (d) eliminate the number of cups and holes on the manifolds. The summaries of the advantages, disadvantages, and tests required to the concepts generated are given in Table 9.

(a) Concept 1 is to remove the nonvalue-adding stainless-steel frames (see Figure 9, $\neq 1$ ) and side brackets (see Figure $9, \neq 7$ ) in the rack structure which are very expensive for non-VDI customers. Most of the non-VDI customers are industrial facilities, the frames and brackets added in the current rack design are not necessary. The metal frames that are used to slide the rack into an AHU unit are needed when cleaning operation is desired. However, thanks to the separation of the markets, the frames are removed as nonvalue-adding because the non-VDI rack does not need removal from the AHU unit for cleaning and can be welded (fixed attachment with AHU) by the users themselves. The cost advantage of this concept is estimated to be $10 \%$ of the rack cost, including material and assembly operation costs.

(b) Concept 2 is to substitute the electronic stainless-steel solenoid drain valves (see Figure $9, \neq 9$ ) with mechanical valves (brass material), which are used to release water once the rack finishes operation. The VDI hygienic requirement dictates materials to be made of stainless-steel that are in contact with the water. However, once the markets are separated, the non-VDI rack version will not require this material. Alternatively, a mechanical and cheaper valve which is made up of brass (copper and zinc) can be used. The market prices for the stainless steel and brass valves are $18 € /$ piece and $5 € /$ piece, respectively (a cost reduction of $13 € /$ piece). Moreover, as the VDI requirement demands a close control on the water quality inside the rack, the drain values are connected with the PLC (Programmable Logic Controller, see Figure 4) using electrical wirings. But, these wirings will not be required in the new rack version. As a result, the cost advantages of this concept come from reducing the material and wiring costs.

(c) Concept 3 is to reduce the number of modulating solenoid valves (see Figure $9, \neq 9$ ) by assigning one valve for two vertical manifolds (see Figure $9, \neq 6$ ). This concept enables the cost reduction by minimizing the number of valves and associated wiring costs used to connect with the PLC system. The price of each valve is about $20 € /$ piece. The cost advantages vary depending on the size of the rack, the smallest and the biggest sizes have 4 and 30 manifolds, respectively. Therefore, the average cost saving per rack is estimated to vary from $40 € /$ rack to $3000 € /$ rack.

(d) Concept 4 is to eliminate the holes and the cubs on the manifolds (see Figure $9, \neq 6$ ). In the current design, the empty holes were used to clean the manifolds when it is thought to be dirty (requirement of VDI). However, in the non-VDI version, the holes and the cups (to close the holes) have no functions, and so are eliminated as nonvalue-adding features. The advantages of the concept are to minimize cups' costs and reduce the time for drilling the holes during manufacturing and assembly operations.

\subsection{Testing concepts}

In SBCE process, consideration of testing the concepts for constraints is important to facilitate the test \& then design paradigm (Kennedy \& Harmon, 2008). For each of the 


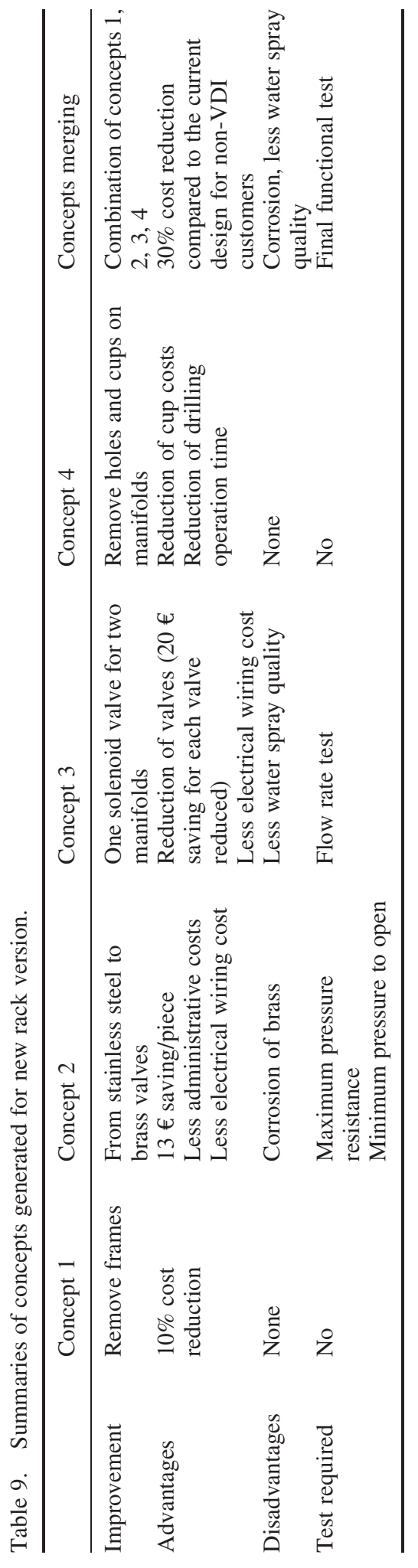


rack concepts generated, the sources of failures are identified as shown in Table 9 to test them before going to detail design phase. Concepts 2 needs "pressure test" and concept 3 needs "flow rate test."

- Pressure tests for concept 2: the mechanical drain valve proposed has never been used before, and need to be tested for the maximum pressure it can withstand, and the minimum pressure at which the valve will close. Three new valves are sourced from three different suppliers and tested for hours to eliminate infeasible suppliers.

- Flow rate test for concept 3: for this concept to work, a single valve has to withstand the maximum water flow rate $(1001 / \mathrm{h}$ ) (see Figure $9, \neq 6)$. The concept has been tested, and it is able to allow the maximum water flow when the number of manifolds is more than 5. Thus, the concept works very well when the number of manifolds is more than 5 .

\subsection{Merging concepts}

All the four concepts are combined to maximize the benefits or the value of the new rack version. Concept merging is synonyms to the convergence process in SBCE. The final merged concept is estimated to have a 30\% cost saving for non-VDI customers; considering all the cost advantages of the four concepts generated. After final functional test, the company is expecting to launch the new rack design to customers. The new version is expected to have high market share as no competitor has a non-VDI rack version (see the competitors' performances of C5 in Figure 5).

\section{Validation of SBCE IR}

The objective of this section is to discuss the validation of SBCE IR using interviews with four experts who are involved in the AHS case study. The questionnaire is categorized into three classes: (i) differences and synergies with existing methods used in the company, this is to investigate the advantages of SBCE IR in supporting existing methods used in the company; (ii) effectiveness of SBCE IR, this is to assess whether the SBCE IR achieves its objectives in terms of reducing the extensive nature of SBCE process, evaluating customer importance and competitive priorities and its contribution to enhance innovation; and (iii) difficulties and applicability of SBCE IR. The results of the interviews are summarized in the following subsections.

\subsection{Differences and synergies of SBCE IR with existing methods}

The case company uses different methods to launch projects: new market requirements, when customers are requesting new improvements; correction of previous failures; technology push, which is related to internal initiatives to design new products and technologies; company strategy, this is related to long-term plans of the company in terms of new products to develop, new markets to enter, and so on; and portfolio management, which is a formal process to prioritize and select projects.

These methods have drawbacks. First, they make the company to react to changes and leave less flexibility to make preplanning. For example, new requirements and field failures can happen any time and the company has to react to these requests. Technology pushes depend on few and highly experienced designers, and can be very random where ideas arise at any time. Second, the methods are based on top-down approach. For instance, portfolio management and company strategy use limited and unsystematic 
information related to customer importance, competitive priorities, and resource availability to select projects to develop. Third, these methods are not based on contradictions. Often projects are chosen based on what seems to be simpler or available ideas are chosen. These limit the potential of the company to offer innovative products to customers.

According to experts, SBCE IR has significant contributions to the above shortcomings. First, SBCE IR is proactive approach. New projects can be identified and prioritized which help the company to plan resource requirements a priori. Second, SBCE IR is based on bottom-up approach. Portfolio managers can use SBCE IR developed for products to make informed decisions to select projects. Third, as SBCE IR is based on contradictions, it gives the opportunity to overcome specific contradictions.

\subsection{Effectiveness of SBCE IR}

The questions here are selected based on the main objectives of the SBCE IR and the criteria used to build it. The results of the response are summarized as follows:

- Extensiveness of SBCE process and SBCE IR: the experts acknowledge the effectiveness of the SBCE IR in terms of its ability to help to target where SBCE should be applied. The focus on contradictions and the prioritization rules provided in the SBCE IR contribute to the effectiveness. However, the experts also noted that SBCE IR should be used as a rough-cut planning methodology than to make final decisions on which contradictions to solve. Other criteria should also be considered to make final decisions (e.g., investment required and company's strategy should also be considered as criteria to select contradictions for SBCE).

- Evaluation of customer value and SBCE IR: the use of AHP method to evaluate customer importance helps to systematically evaluate the requirements. However, the experts underlined two important considerations. First, the list of requirements should also include future predictions on emerging needs. Otherwise, the SBCE IR becomes unstable as customers often change requirements or new requirements can emerge. Therefore, designers and mangers building the roadmap should make careful investigations on the future needs and they should create close collaborations between customers to identify list of requirements. The second note is related to the variety of customers the case company should satisfy. For example, the case company has multiple levels of customers which often have different priorities. Taking AHS as an example, there are four layers of customers: contractors, who buy large quantities; installers, who buy the product from contractors and install it at customer sites; Original Equipment Manufacturers, who directly buy the product from the company; and final customers, who are using the product. Therefore, while assigning judgment on the importance for requirements in the first step of SBCE IR, care must be taken to balance the needs of the different customers.

- Evaluation of competitive products and SBCE IR: the experts acknowledge the effectiveness of the SBCE IR in evaluating competitive products. Understanding performance gaps with competitors and using $D_{j}$ (see Equation (5)) give rough indications of the technological gaps to fulfill and the efforts required. However, the experts noted a drawback in using competitors benchmarking. In particular, in the case of developing new generation of products that might require radical changes where competitors use significantly different solutions, there might not be data or $D_{j}$ becomes less useful. In this situation, ranking of independent contradictions can be based on $\mathrm{GW}\left(r_{j}\right)$ along with other criteria such as investment, resources, and knowhow required to overcome contradictions. 
- SBCE IR and enhancing innovation: the effectiveness of idea generation phase can be assessed taking four measures (Shah et al., 2002): quantity, the total number of ideas generated; quality, the feasibility of an idea and how close it comes to meet customer requirements; novelty, how unusual or unexpected an idea is as compared to other ideas; and variety, the distinctiveness of the ideas generated. For quantity and quality, the experts agree on the effectiveness of SBCE to enhance these measures. In particular, if the idea generation process in SBCE is supported by methods such as TRIZ, designers will have the opportunity to structure design problems to explore more ideas. The use of SBCE principles of communication and extensive testing before commitment increase the chance of achieving expected quality of the final concept. However, novelty and variety largely will depend on the experience and imaginations of designers involved. Such limitations imply that personal skills and experiences will have impacts on the effectiveness of SBCE IR.

\subsection{Difficulties and applicability of SBCE IR}

It is not difficult to build the SBCE IR for products. But, it is time-consuming to collect data to build it for very new products. Possible remedies are suggested. First, the full version can be used for mature products or family of products to identify and prioritize improvement areas. Second, for very new products, SBCE not necessarily starts to overcome contradictions. Rather, SBCE begins to satisfy a requirement or list of requirements or certain company's strategies. Even so, while developing radical design, designers might face non-typical problems that are difficult to solve with typical solutions. Industries primarily use brainstorming to explore ideas, but it is not effective to solve nontypical problems and success might not be assured. In this case, formulating a problem into a contradiction, and generating solutions might result into acceptable final solution. Therefore, for radical designs, some steps of SBCE IR can be used in a particular problemsolving process (e.g., steps 3, 4, and 6).

\section{Conclusions and future research}

The main purpose of this paper has been to develop a methodology that guides designers to make rational choices to start SBCE process. The efforts made in conducting SBCEs should focus on addressing the right problems to maximize customer value and improve competitiveness. No previous literature provides the required methodology for this purpose.

The proposed SBCE IR uses the TRIZ's concept of contradictions as design problems to start SBCE processes. SBCE IR contributes to TRIZ, QFD, and SBCE literature by utilizing the synergies between them, and provides systematic prioritization schemes to select contradictions.

Moreover, the case study on AHS has shown that there are benefits for the industry. The roadmap helps to identify 23 potential areas of contradictions to improve the current AHS design. Designers conducted SBCE process on the rack subsystem and its components. The case company expects significant cost reductions for growing nonVDI6022 customers. The new rack version is under development to be launched to the market. Furthermore, the methodology has been effective to make preplanning SBCE projects.

Some further researches, however, are awaited to improve the limitations of SBCE IR. First, additional criteria are needed to make the ranking of contradictions more robust. 
Future researches might also use value-based approach to rank contradictions taking criteria that reflect the "cost" (in terms of resource requirements, know-how, technology, etc.) and "benefit" (in terms of revenue, cost savings, etc.). Second, different levels of customers and their importance are not treated in evaluating $\mathrm{GW}\left(r_{j}\right)$. Future researches might consider a way to integrate different customer needs into SBCE IR.

\section{Acknowledgements}

This research has been conducted as part of a European project titled "Lean Product and Process Development (LeanPPD)" (NMP-2008-214090). The authors acknowledge the European Commission for its financial support and the project's partners for their comments and suggestions during the preparation of this paper. Moreover, the authors thank managers and designers at Carel Industries that who been involved in the research.

\section{Funding}

This work was supported by The European Commission [grant number 214090].

\section{Notes}

1. Email: marco.taisch@polimi.it

2. Email: sergio.terzi@unibg.it

3. Email: walter.bessega@carel.com

4. Email: alberto.rosso@carel.com

5. The causal relations can be read from matrix obtained using Equation (6). To determine whether relationships between contradictions are strong, a threshold matrix should be defined. For example, some authors suggest a threshold of 0.2 (Lee et al., 2010). Those contradictions that have more than or equal to 0.2 relations coefficients in the matrix can be considered to have strong relations.

\section{References}

Akao, Y., \& Mazur, G. H. (2003). The leading edge in QFD: Past, present and future. International Journal of Quality \& Reliability Management, 20, 20-35.

Al-Ashaab, A., Shehab, E., Alam, R., Sopelana, A., Sorli, M., Flores, M., \& James-Moore, M. (2010). The conceptual leanPPD model. The 17th ISPE international conference on Concurrent Engineering, September, Cracow, Poland.

Altshuller, G. (1984). Creativity as an exact science. New York: Gordon \& Breach.

Altshuller, G. (1994). And suddenly the inventor appeared (L. Shulyak, Trans.). Worcester, MA: Technical Innovation Centre. ISBN 0-9640740-1-X.

Altshuller, G. (1999). The innovation algorithm: TRIZ, systematic innovation, and technical creativity. Worcester, MA: Technical Innovation Centre. ISBN 0-9640740-4-4.

Baldussu, A., Becattini, N., \& Cascini, G. (2011). Network of contradictions analysis and structured identification of critical Control Parameters. Procedia Engineering, 9, 3-17.

Bhushan, N. (2007). Set-based concurrent engineering (SBCE) and TRIZ - A framework for global product development. India: Wipro Technologies.

Bogus, S. M., Molenaar, K. R., \& Diekmann, J. E. (2005). A concurrent engineering approach to reducing design delivery time. ASCE Journal of Construction Engineering and Management, $131,1179-1185$.

Cavallucci, D., \& Khomenko, N. (2007). From TRIZ to OTSM-TRIZ: Addressing complexity challenges in inventive design. International Journal of Product Development, 4, 4-21.

Fontela, E., \& Gabus, A. (1974). DEMATEL - Progress achieved. Futures, 6, 361-363.

Fontela, E., \& Gabus, A. (1978). World Crisis - Decision Making Trial and Evaluation Laboratory. Futuribles, 14, 211-221.

Ford, D. N., \& Sobek, D. K. (2005). Adapting real options to new product development by modeling the second Toyota Paradox. IEEE Transactions on Engineering Management, 52, 175-185. 
Forman, E. H. (1990). Random indices for incomplete pairwise comparison matrices. European Journal of Operational Research, 48, 153-155.

Garcia, M. L., \& Bray, O. H. (1997). Fundamentals of technology roadmapping. SAND97-0665. Albuquerque, NM: Sandia National Laboratories.

Hey, J. H. G., Joyce, C. K., \& Beckman, S. L. (2007). Framing innovation: Negotiating shared frames during early design phases. Journal of Design Research, 6, 79-99.

Hua, Z., Yang, J., Coulibaly, S., \& Zhang, B. (2006). Integration TRIZ with problem-solving tools: A literature review from 1995 to 2000. International Journal of Business Innovation and Research, 1, 111-128.

Kennedy, M. N., \& Harmon, K. (2008). Ready, set, dominate: Implement Toyota's set-based learning for developing products and nobody can catch you. Richmond, VA: Oaklea Press.

Khan, M., Al-Ashaab, A., Shehab, E., Haque, B., Ewers, P., Sorli, M., \& Sopelana, A. (2011). Towards lean product and process development. International Journal of Computer Integrated Manufacturing, [online] http://www.tandfonline.com/doi/abs/10.1080/0951192X.2011. 608723?tab= permissions\#tabModule (Accessed January 2013).

Khomenko, N., De Guio, R., Lelait, L., \& Kaikov, I. (2007). A framework for OTSM-TRIZ based computer support to be used in complex problem management. International Journal of Computer Applications in Technology, 30, 88-104.

Kline, S. J., \& Rosenberg, N. (1986). An overview of innovation. In: R. Landau \& N. Rosenberg (Eds.), The positive sum strategy: Harnessing technology for economic growth (p. 287). Washington, DC: National Academy Press.

Kowalick, J. (1998). Psychological Inertia. TRIZ Journal, [online] http://www.triz-journal.com/ archives/1998/08/c/index.htm (Accessed July 2012).

Lee, Y., Li, M., Yen, T., \& Huang, T. (2010). Analysis of adopting an integrated DEMATEL on a technology acceptance model. Expert System with Application, 37, 1745-1754.

Maher, M. L., \& Poon, J. (1996). Modelling design exploration as co-evolution. Microcomputers in Civil Engineering, 11, 195-210.

McManus, H. L. (2005). Product Development Value Stream Mapping (PDVSM) Manual. Cambridge, MA: Massachusetts Institute of Technology, Lean Aerospace Initiative.

Mizuyama, H., \& Ishida, K. (2007). Systematic decision making process for identifying the contradictions to be tracked by TRIZ to accomplish product innovation. Journal of Automation, Mobile Robotics \& Intelligent Systems, 1, 21-29.

Morgan, J. M., \& Liker, J. K. (2006). The Toyota product development system: Integrating people, process, and technology. New York, NY: Productivity Press.

Oosterwal, D. P. (2010). The lean machine: How Harley-Davidson drove top-line growth and profitability with revolutionary lean product development. New York: American Management Association.

Oppenheim, B. W. (2004). Lean product development flow. Systems Engineering, 7, 352-378.

Phaal, R., Farrukh, C., \& Probert, D. (2010). Roadmapping for strategy and innovation: Aligning technology and markets in a dynamic world. Cambridge: Institute of Manufacturing, University of Cambridge.

Raudberget, D. (2010). Practical applications of set-based concurrent engineering in industry. Journal of Mechanical Engineering, 56, 685-695.

Rossi, M., Kerga, E., Taisch, M., \& Terzi, S. (2011). Proposal of a method to systematically identify wastes in new product development process. IEEE Proceeding of the 7 th international conference on Concurrent Enterprise (ICE2011), Aachen (Germany), June 20-22.

Rossi, M., Kerga, E., Taisch, M., \& Terzi, S. (2012). Learning methodologies to diffuse lean product development to industries. The 9th international conference on Product Lifecycle Management, PLM2012, Vol. 388, pp. 287-298, July 9-11 2012, Montreal, Canada, ISBN print: 978-3-642-35757-2, ISBN online: 978-3-642-35758-9, doi: 10.1007/978-3-642-35758-9_25.

Saaty, T. (1980). The analytic hierarchy process. New York: McGraw-Hill.

Savransky, S. D. (2000). Engineering of creativity - Introduction to TRIZ methodology of inventive problem solving (1st ed.). Boca Raton, FL: CRC Press.

Shah, J. J., Vargas-Hernandez, N., \& Smith, S. M. (2002). Metrics for measuring ideation effectiveness. Design Studies, 24, 111-134.

Sheng, I. L. S., \& Kok-Soo, T. (2010). Eco-efficient product design using theory of inventive problem solving (TRIZ) principles. American Journal of Applied Science, 7, 852-858. 
Shi, G., \& She, Y. (2008). Theoretical research to solve the problem based on QFD, TRIZ and Taguchi method. Systems Engineering and Electronic Technology, 30, 851-857.

Smithers, T. (1989). AI-based design versus geometry-based design or why design cannot be supported by geometry alone. Computer-Aided Design, 21, 141-150.

Sobek, D. K. (1997). Principles that shape product development system - A Toyota and Chrysler comparison (PhD. Dissertation). Industrial and Operations Engineering, University of Michigan.

Sobek, D. K., Ward, A. C., \& Liker, J. K. (1999). Toyota's principles of set-based concurrent engineering. Sloan Management Review, 40, 67-83.

Terwiesch, C., Loch, C. H., \& De Meyer, A. (2002). Exchanging preliminary information in concurrent engineering: Alternative coordination strategies. Organization Science, 13, $402-419$.

Wang, H., Chen, G., Lin, Z., \& Wang, H. (2005). Algorithm of integrating QFD and TRIZ for the innovative design process. International Journal of Computer Applications in Technology, 23, $41-52$.

Ward, A., Liker, J. K., Cristiano, J. J., \& Sobek, D. K II (1995). The second Toyota Paradox: How delaying decisions can make better cars faster. Sloan Management Review, 36, 43-61.

Ward, A. C., Shook, J. K., \& Sobek, D. K. (2007). Lean product and process development. Cambridge, MA: The Lean Enterprise Institute.

Womack, J. P., \& Jones, D. T. (2005). Lean solutions: How companies and customers can create value and wealth together. Brookline, MA: Lean Enterprise Institute.

Yamashina, H., Ito, T., \& Kawada, H. (2002). Innovative product development process by integrating QFD and TRIZ. International Journal of Production Research, 40, 1031-1050.

Zeng, Y., \& Cheng, G. (1991). On the logic of design. Design Studies, 12, 137-141. 